\title{
Genetic interaction network of the Saccharomyces cerevisiae type I phosphatase Glc7
}

\author{
Michael R Logan ${ }^{1,2}$, Thao Nguyen ${ }^{1}$, Nicolas Szapiel1, James Knockleby¹, \\ Hanting Por ${ }^{1}$, Megan Zadworny ${ }^{1}$, Michael Neszt ${ }^{2}$, Paul Harrison ${ }^{1,3}$, \\ Howard Bussey ${ }^{1,3}$, Craig A Mandato*1,2, Jackie Vogel*1,3,4 and \\ Guillaume Lesage*4
}

\begin{abstract}
Address: ${ }^{1}$ Department of Biology, McGill University, Montreal (QC), Canada, ${ }^{2}$ Anatomy and Cell Biology, McGill University Montreal (QC), Canada, ${ }^{3}$ Developmental Biology Research Initiative, McGill University, Montreal (QC), Canada and ${ }^{4}$ Cell Imaging and Analysis Network (CIAN), McGill University, Montreal (QC), Canada

Email: Michael R Logan - logan@ualberta.ca; Thao Nguyen - thaocad@yahoo.com; Nicolas Szapiel - mikolaj.szapiel@mail.mcgill.ca; James Knockleby - James.Knockleby@mcgill.ca; Hanting Por - hanting.por@mcgill.ca; Megan Zadworny - megan.zadworny@mcgill.ca; Michael Neszt - michael.neszt@mail.mcgill.ca; Paul Harrison - paul.harrison@mcgill.ca; Howard Bussey - howard.bussey@mcgill.ca; Craig A Mandato* - craig.mandato@mcgill.ca; Jackie Vogel* - jackie.vogel@mcgill.ca; Guillaume Lesage* - guillaume.lesage@mcgill.ca

* Corresponding authors
\end{abstract}

Published: 15 July 2008

BMC Genomics 2008, 9:336 doi:10.1186/147|-2164-9-336
Received: I May 2008

Accepted: 15 July 2008

This article is available from: http://www.biomedcentral.com/I47I-2/64/9/336

(c) 2008 Logan et al; licensee BioMed Central Ltd.

This is an Open Access article distributed under the terms of the Creative Commons Attribution License (http://creativecommons.org/licenses/by/2.0), which permits unrestricted use, distribution, and reproduction in any medium, provided the original work is properly cited.

\begin{abstract}
Background: Protein kinases and phosphatases regulate protein phosphorylation, a critical means of modulating protein function, stability and localization. The identification of functional networks for protein phosphatases has been slow due to their redundant nature and the lack of large-scale analyses. We hypothesized that a genome-scale analysis of genetic interactions using the Synthetic Genetic Array could reveal protein phosphatase functional networks. We apply this approach to the conserved type I protein phosphatase Glc7, which regulates numerous cellular processes in budding yeast.

Results: We created a novel g/c7 catalytic mutant (g/c7-E/OIQ). Phenotypic analysis indicates that this novel allele exhibits slow growth and defects in glucose metabolism but normal cell cycle progression and chromosome segregation. This suggests that glc7-EIOIQ is a hypomorphic glc7 mutant. Synthetic Genetic Array analysis of glc7-EIOIQ revealed a broad network of 245 synthetic sick/lethal interactions reflecting that many processes are required when Glc7 function is compromised such as histone modification, chromosome segregation and cytokinesis, nutrient sensing and DNA damage. In addition, mitochondrial activity and inheritance and lipid metabolism were identified as new processes involved in buffering Glc7 function. An interaction network among 95 genes genetically interacting with GLC7 was constructed by integration of genetic and physical interaction data. The obtained network has a modular architecture, and the interconnection among the modules reflects the cooperation of the processes buffering Glc7 function.

Conclusion: We found 245 genes required for the normal growth of the g/C7-EIOIQ mutant. Functional grouping of these genes and analysis of their physical and genetic interaction patterns bring new information on Glc7-regulated processes.
\end{abstract}




\section{Background}

Regulation of phosphorylation state is a mechanism for controlling the function, localization and stability of proteins in vivo and is critical for the regulation of essential processes such as polarity and morphogenesis, chromosome segregation, cytokinesis, and cell cycle control [1-4]. Together, protein kinases (which mediate phosphorylation) and protein phosphatases (PPases) (which mediate de-phosphorylation) provide precise temporal and spatial regulation of their target substrates. In the budding yeast Saccharomyces cerevisiae, the dynamic localization of PPases suggests that an extensive cross talk between these processes is critical for the proper execution of cell division $[2,5]$. However, many of the substrates and regulatory proteins that participate in this cross talk remain unidentified. Insight into PPase function has lagged significantly in comparison to kinases since PPases: (1) frequently require regulatory proteins that determine their targeting to particular substrates, cellular location or process and (2) often exhibit considerable functional redundancy. In budding yeast, for example, 90\% of the known 32 PPases are non-essential [6].

Study of genetic interaction networks is a powerful means to get insight into gene function, and several high throughput methods were developed during the last decade to generate genome-wide maps of genetic interactions [7-13]. However, such maps are still missing for yeast PPases. To date investigations of PPase function in budding yeast have utilized mutations outside the catalytic site $[5,14-16]$ or probed genetic interactions using single or double knockout PPase mutations [6]. These approaches present constraints for large-scale analysis of PPase function since: (1) mutations outside the catalytic domain generally affect the formation of a specific class of holoenzyme or the ability to interact with co-factor(s) required for the proper targeting of the PPase to a subset of substrates [17-19], and (2) the use of knockout alleles, in addition to precluding the analysis of the essential PPases, may lead to promiscuous and/or low-affinity interaction of regulatory subunits with PPases of the same class. For these reasons, we designed a strategy based on a hypomorphic catalytic PPase mutation that uses the Synthetic Genetic Array (SGA). This method generates a large number of double mutant combinations, and has been successfully used to identify genetic interaction networks in yeast in a wide range of cellular processes $[12,13,20,21]$.

In the budding yeast Saccharomyces cerevisiae, 32 genes encode predicted or demonstrated catalytic subunits of PPases. Only two of these PPases are clearly essential: the PP1-type PPase, Glc7 (glycogen deficient) [1,22], and Cdc14 (cell division cycle), a dual-specificity phosphatase that regulates mitotic/meiotic exit [23]. We selected Glc7 for our analyses since a framework of genetic and protein interactions exists from previous studies of conditional glc7 mutants, but a comprehensive large-scale genetic analysis had not yet been performed. Glc7 critically regulates numerous processes such as glucose and glycogen metabolism, sporulation, chromosome segregation, meiosis, mRNA transport, transcription, and amino acid biosynthesis $[1,3,15,17,22,24,25]$. A search in the BioGRID database (version 2.0.41, June 1, 2008 [26]) returned a list of 114 proteins reported to physically interact with Glc7. Some of these proteins are known substrates (Cbf2, Fin1, Red1, Gsy2), while others are thought to be regulatory subunits (Gac1, Reg1, Reg2, Ref2, Sip5, Glc8, Bud14, Bni4, Sds22). However, the functional significance of the majority of these interactions remains unclear. In contrast, only 30 genes have been reported to show genetic interactions with various $g l c 7$ mutants. The vast majority of these genetic interactions are dosage dependent and only 7 genes (BUD14, DAM1, DOC1, GLC8, RHR2,SET1 and SLT2) have been reported to show synthetic lethal/ sick interaction with different conditional $g l c 7$ alleles. The functional clustering of genetic interactions of conditional glc7 alleles suggests the majority of these mutations compromise specific aspects of Glc7 function. As such, these alleles are highly suited for cell biology. However an unbiased large-scale analysis revealing a comprehensive picture of Glc7 signaling in vivo requires a novel glc7 allele affecting many functions of Glc7 at a time.

In an effort to further define the signaling network for Glc7, we created a novel glc7 catalytic mutant (glc7E101Q) suitable for SGA. The glc7-E101Q mutant exhibited slow growth and impaired glycogen accumulation on glucose, but no specific delay in the cell cycle. The impaired growth and defects in glycogen synthesis of the glc7-E101Q mutant were rescued by introduction of a single copy of wild type GLC7, indicating that glc7-E101Q is a recessive, hypomorphic allele. SGA analysis revealed a broad network of 245 synthetic sick/lethal (SSL) interactions that encompassed all known Glc7-regulated processes, and suggested additional previously unknown functions for Glc7.

\section{Results \\ Creation of a catalytic-deficient GLC7 mutant, glc7- EIOIQ}

Glc7 is the sole essential member of the PPP family of PPases in budding yeast and members of this family share a conserved catalytic motif. Residues in the Glc7 catalytic domain (CD1-3) are evolutionarily conserved with human PP1 orthologs and the PP1-like bacterial $\lambda$-PPASE (Figure 1A). Given the high degree of conservation in the catalytic residues, Glc7 is expected to have catalytic characteristics similar to those of previously characterized PP1-type PPases. Phosphate hydrolysis by PP1 occurs via 
A

PP1 catalytic domain ( $\sim 0$ residues)

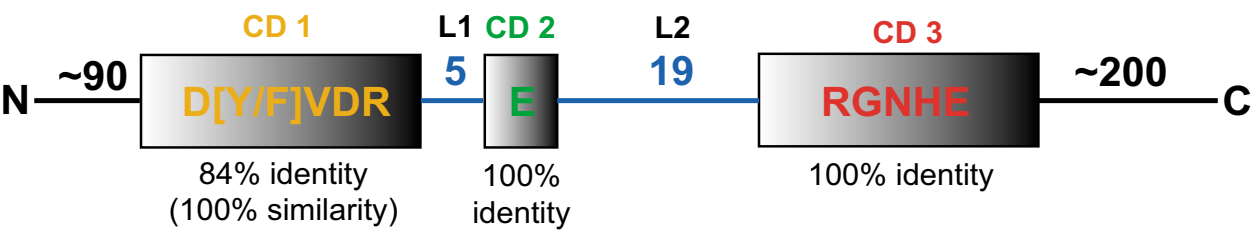

CD 1 CD 2

CD 3

PP1_ $\gamma(H S)$ LFEYGGFPP-ESNYLFLGDYVDRGKQSLETICLLLAYKIKYPENFFLIRGNHECASINRI PP1 $1 \alpha$ (HS) -----FPP-ESNYLFLGDYVDRGKQSLETICLLLAYKIKYPENFFLLRGNHECASINRI PP1_2 $\alpha$ (HS) LFEYGGFPP-ESNYLFLGDYVDRGKQSLETICLLLAYKIKYPENFFLLRGNHECASINRI PP1 $3 \alpha$ (HS) LFEYGGFPP-ESNYLFLGDYVDRGKQSLETICLLLAYKIKYPENFFLLRGNHECASINRI $\lambda$-PPase KLDTIGFDNKKDLLISVGDLVDRGAENVECLELITFP------WFRAVRGNHEQMMIDGL ब|GLC7 LFEYGGFPP-ESNYLFLGDYVDRGKQSLETICLLLAYKIKYPENFFILRGNHECASINRI

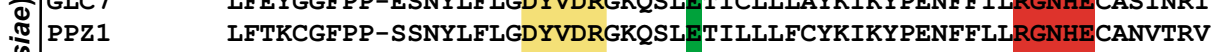

PPZ2

SAL6

¿ PPH21

(5) $\mathrm{PPH} 22$

PPH1

\& $\mathrm{PPH} 3$

PPG1

PPT1

CNA1 LFTKCGFPP-SSNYLFLGDYVDRGKQSLETILLLFCYKIKYPENFFLLRGNHECANVTRV
LFTKCGFPP-MANYLFLGDYVDRGKOSLETILLLLCYKIKYPENFFLLRGNHECANVTRV ILKLSGVPS-DTNYLFLGDYVDRGKNSLETILLLLCYKIKYKDNFFMLRGNHESANVTKM LFKIGGPCP-DTNYLFMGDYVDRGYYSVETVSYLVAMKVRYPHRITILRGNHESROITQV LFKIGGPCP-DTNYLFMGDYVDRGYYSVETVSYLVAMKVRYPHRITILRGNHESRQITQV LFRTAGGFPDDINYIFLGDYVDRGYYSLETFTLLMCLKVKYPAKITLVRGNHESRQITQV LFEKSGGVE-KTRYIFLGDFVDRGFYSLESFLLLLCYKLRYPDRITLIRGNHETRQITKV IFQIGGPVP-DTNYLFLGDYVDRGLYSVETIMLLIVLKLRYPSRIHLLRGNHESROITQS LFRKFGKVGPKHTYLFNGDFVDRGSWSCEVALLFYCLKILHPNNFFLNRGNHESDNMNKI LFEVGGDPA-EIDYLFLGDYVDRGAFSFECLIYLYSLKLNNLGRFWMLRGNHECKHLTSY LFEVGGDPA-TTSYLFLGDYVDRGSFSFECLIYLYSLKLNFNDHFWLLRGNHECKHLTSY

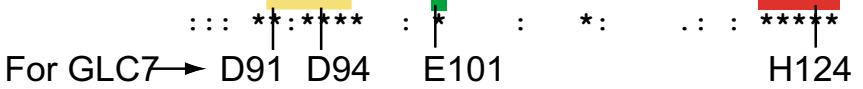
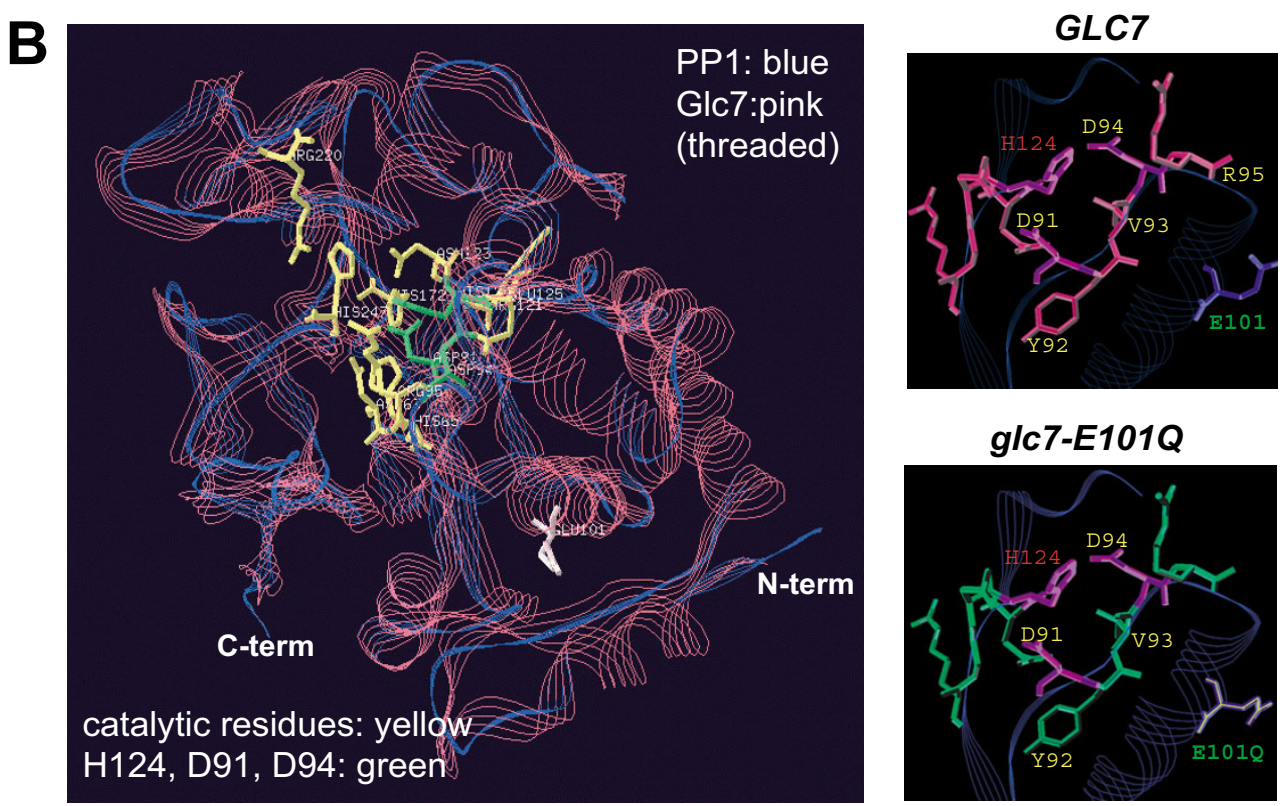

\section{Figure I}

Structure of PP I catalytic motif and the glc7-E I0IQ mutant. (A) PPI protein phosphatases have highly conserved catalytic domains, consisting of residues acting as an acidic catalyst for phosphotransfer (CDI and CD2) from the substrate and a phospho acceptor hisidine residue (CD3). Residues in the catalytic pocket are highly conserved between human (PPI), yeast PPP-type PPases (Glc7 and others) and the bacterial PPase, $\lambda$-PPASE. (B) Left panel: The Glc7 catalytic pocket (pink) was modeled using the tertiary structure of human PPIC- $\gamma$ (PDB Model ljk7A; blue). Right panels: The EIOIQ mutation is predicted to inhibit the binding of a metal cation required to accelerate phospho-transfer to HI24, but to not alter the shape/size of the catalytic pocket relative to wild type Glc7. 
a onestep reaction and is dependent on metal ion catalysts $\left(\mathrm{Mn}^{2+}\right.$ and $\left.\mathrm{Fe}^{2+}\right)$. This hydrolysis reaction (Additional File $1)$ is dependent on a phosphoesterase motif $\operatorname{DXH}(\mathrm{X})_{\mathrm{n}} \mathrm{GDXXD}(\mathrm{X})_{\mathrm{n}} \mathrm{GNHD} / \mathrm{E}$ (where $\mathrm{n}=\sim 25$ amino acids) whose active residues are a general acid catalyst (H124 in Glc7) and the carboxyl oxygen of two invariant aspartic acids (D91 and D94 in Glc7) [27]. Similar to human PP1 and Glc7, $\lambda$-PPASE (a bacteriophage ortholog of PP1) shares this conserved catalytic domain (Figure 1A) and has been previously examined in structure-function analyses of the active residues in the catalytic pocket. Mutation of either D49 or D52 (D92 and D95 in PP1C- $\gamma$; D91 and D94 in Glc7, respectively) to a non-reactive asparagine residue $(\mathrm{D}>\mathrm{N})$ resulted in a catalytically dead enzyme in in vitro PPase assays. However, mutation of E59 (E>Q; E102 in PP1C and E101 in Glc7) reduced the catalytic activity of $\lambda$-PPASE $\sim 8$ fold and impaired $\mathrm{Mn}^{2+}$ recruitment, but did not significantly alter its substrate binding [28]. An E>Q substitution in the equivalent residue of Glc7 (E101Q) is therefore predicted to reduce catalytic activity by perturbing the recruitment of the metal co-factor that enhances phospho-transfer. Using human PP1C- $\gamma$ as a template, we found that the conserved residues of Glc7 in the CD1-3 regions form a tertiary structure very similar to human PP1. Furthermore, analysis of the 3D model of the E101Q mutation in Glc7 indicated that the overall shape and size of the catalytic pocket was not significantly changed (Figure $1 \mathrm{~B}$ ). We predicted that reduction of Glc7 catalytic activity in vivo, as a result of the E101Q mutation, would result in a recessive, hypomorphic glc7 allele suitable for an unbiased SGA analysis.

\section{glc7-E I 0 I Q mutant exhibits slow growth but no appreciable cell cycle delay or defect in chromosome segregation}

The introduction of a $g l c 7-D 91 \mathrm{~N}$ mutation into diploid cells resulted in inviable haploid progeny by tetrad dissection (data not shown). This finding is consistent with the previous observation that this mutation results in a catalytically dead form of the enzyme in vivo [28]. In contrast, haploid glc7-E101Q colonies isolated by tetrad dissection were viable but consistently small compared to wild type (GLC7) when grown on rich medium (YPAD) (data not shown). Analysis of the growth curve for three haploid isolates of glc7-E101Q indicated impaired kinetics compared to wild type cells (Figure 2A). To determine whether slow growth was due to a delay in cell cycle progression, mutant and wild type cells from log phase cultures were harvested, stained with propidium iodide and DNA content measured by FACS analysis. As shown in Figure 2B, FACS analysis revealed that proportion of G1, S, or Mphase cells in glc7-E101Q cultures was not statistically different from that of wild type cells. This result correlated with the observation that proportion of unbudded, small- budded and large-budded cells was similar between wild type and glc7-E101Q strains (Figure 2C).

Studies using conditional glc7 mutants have demonstrated a role for Glc7 in the attachment of spindle microtubules to kinetochores during metaphase and chromosome segregation [1,29-33]. Therefore, we next examined glc7-E101Q cells for chromosome segregation defects and sensitivity to the microtubule-destabilizing agent, benomyl. To examine bi-orientation of sister chromatids, anaphase cells (mitotic spindle>2.5 $\mu \mathrm{m}$ ) expressing GFP-LacI and centromeric repeats (CEN15) of the lactose operon (lacO) [34] were examined by fluorescence microscopy. As shown in Figure 2D, GFP-LacI segregated to both spindle pole bodies (marked by the spindle pole marker, Spc29-CFP) in a similar manner to wild type cells. We also examined for chromosome mis-segregation in glc7-E101Q cells following several growth cycles using a sectoring assay [35]. Wild type, glc7-E101Q and ame1-6 (positive control) strains lacking a functional ADE2 gene (ade24-101) were transformed with a centromeric fragment of chromosome III containing the SUP11 gene (Circle III/SUP11) and analyzed for loss of the fragment after 4-day incubation on YPD medium lacking adenine. The ame1-6 strain exhibited frequent chromosome loss as indicated by the appearance of red sectors in the colonies (Figure 2E). In contrast, glc7-E101Q and wild type colonies induced negligible loss of the Circle III/SUP11 fragment, and the vast majority of colonies remained white in coloration (Figure 2E). We also tested glc7-E101Q cells for sensitivity to the microtubule-disrupting agent, benomyl. When compared to the wild type, glc7-E101Q cells had consistently slower growth on both DMSO control and benomyl plates. However, the slow growth of glc7-E101Q was not exacerbated by benomyl treatment (Figure 2F).

To investigate the possibility that the slow growth phenotype of glc7-E101Q cells might be the result of either protein instability or changes in protein modifications to Glc7, whole cell extracts were examined by Western blot analysis. Protein extracts from strains expressing Glc7ProA or $g l c 7-E 101 Q$-ProA fusion proteins were prepared from asynchronous cells (1D immunoblot) or from G1, S and G2/M-arrested cells (2D immunoblot) and examined using anti-ProA antibodies. The abundance of the glc7E101Q-ProA mutant was not reduced relative to wild type Glc7-ProA by 1D immunoblot analysis (Additional File $2 \mathrm{~A}$ ). Furthermore, in each case, a single isoform was identified for Glc7-ProA and glc7-E101Q-ProA in extracts derived from G1, S and G2/M arrested cells (Additional File $2 \mathrm{~B}$ ). These findings indicate that the slow growth of glc7-E101Q strains was not the result of protein instability or the accumulation of aberrant modifications to the Glc7 protein. 
A

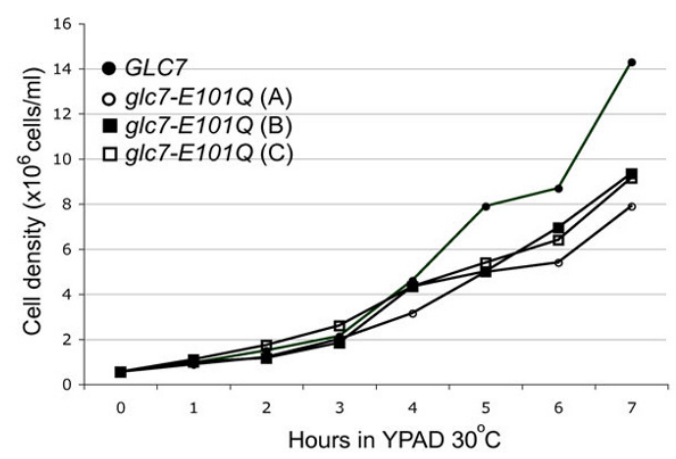

C

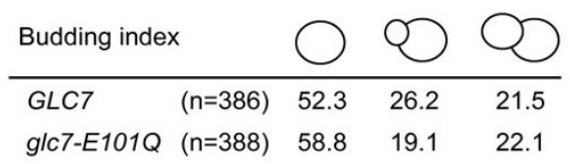

D

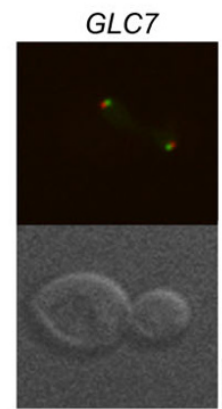

$98 \pm 2 \%$

F
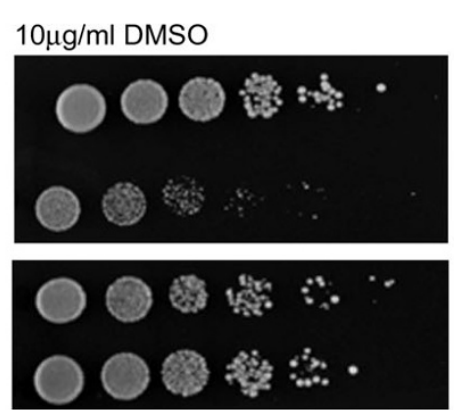

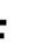

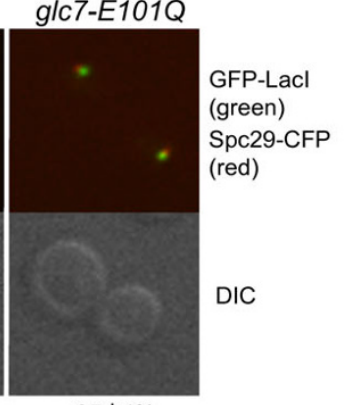

B
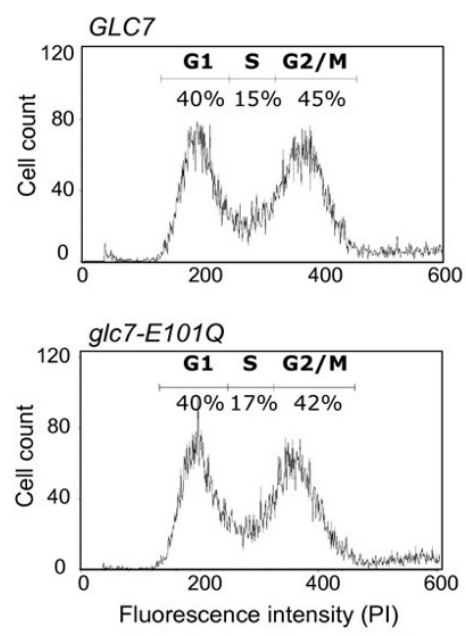

E

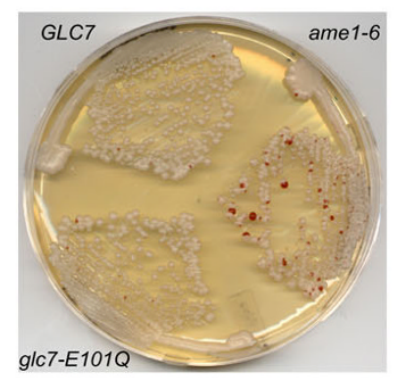

$10 \mu \mathrm{g} / \mathrm{ml}$ benomyl

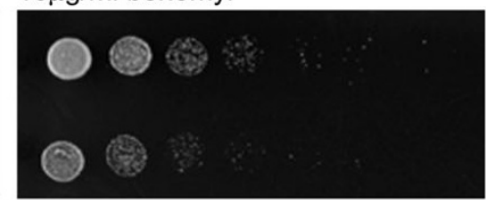

GLC7

glc7-E101Q

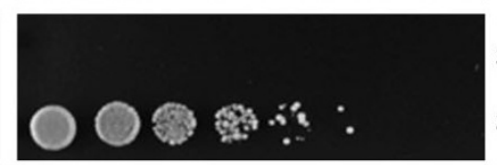

tub1-1

tub2-104

\section{Figure 2}

glc7-EIOIQ mutant exhibits slow growth but no appreciable delay in the cell cycle or chromosome segregation defect. (A) The growth of wild type (GLC7) vs glc7-E IOIQ strains in rich medium (YPAD) was determined from early logphase cultures. (B) FACs analysis for DNA content (propidium iodide staining) of log-phase wild type and glc7-E/0IQ cells. Cell counts are shown plotted against fluorescence intensity (PI). (C) Budding index of wild type and glc7-EIOIQ mutant strains. (D) Fluorescence microscopy of anaphase cells (mitotic spindle $>2.5 \mu \mathrm{m}$ ) wild type and glc7-E $10 / \mathrm{Q}$ cells expressing a chromosome [GFP-Lacl (green) and centromeric (CENI5) repeats of the lactose operon (lacO)] and spindle pole body (SPB) [Spc29-CFP (red)] markers. The percentage of cells with chromosomes localized to both SPBs is indicated at the bottom ( $\mathrm{n}=3,300$ cells/ experiment). (E) Test for chromosome segregation using a sectoring assay. Wild type GLC7, glC7-EIOIQ and ame I-6 strains lacking a functional ADE2 gene (ade2 $4-I O I)$ and transformed with a Circle III/SUPII were plated on to medium lacking adenine (YPD) and scored for appearance of red sectors after 4-day incubation. (F) Spotting assay of glc7-EIOIQ vs. wild type on DMSO control or benomyl plates (5-fold serial dilutions of $1.0 \times 10^{6} \mathrm{cell} / \mathrm{s} / \mathrm{ml} ; 5 \mu \mathrm{l} / \mathrm{spot}$ ). Benomyl-sensitive (tubl-l) and resistant (tub2-104) strains were plated as controls. 


\section{glc7-E I O I Q mutant is impaired in glucose metabolism}

Glc7 has a well-established role in glucose metabolism. The first conditional allele of $g l c 7$ ( $g l c 7-1)$ was isolated as a consequence of its defect in glycogen synthesis in the presence of glucose [36], a phenotype that has, similarly, been observed for other $g l c 7$ mutants $[22,36]$. The failure to accumulate glycogen has been linked to impaired dephosphorylation of the glycogen synthase, Gsy2, by Glc7 and its targeting subunit, Gac1 [15,37]. Glc7 also plays an important role in glucose repression, a process that (in the presence of glucose) leads to transcriptional repression of genes involved in the utilization of alternative carbon sources such as sucrose, galactose and maltose. Conditional glc7 mutants such as glc7-T152K [25,38], glc7F256A, glc7-F292A, glc7-E241 L242 [16] exhibit defects in glucose repression that is due, in part, to an impaired ability of the Glc7 mutant to associate with the targeting subunit Reg1. In the presence of glucose, Glc7-Reg1 has been shown to de-phosphorylate and thereby, inhibit Snf1 kinase, which is responsible for the transcription of several glucose-repressed genes [25,39]. We observed that glc7-E101Q cells had a more significant growth defect in limited glucose (2\% glycerol, $0.08 \%$ glucose; YPAG) rela- tive to its growth in rich medium (2\% glucose; YPAD). Growth of glc7-E101Q cells on both YPAD and YPAG was similar at $30^{\circ} \mathrm{C}$ and $37^{\circ} \mathrm{C}$, indicating the glc7-E101Q mutation does not induce temperature-sensitivity (Figure 3A). Glycogen content was assessed by iodine staining [40] and revealed impaired glycogen accumulation for glc7-E101Q cells (Figure 3B). Both the impaired growth and the glycogen accumulation defects of glc7-E101Q were restored to wild type levels in strains that expressed an un-linked copy of wild type GLC7:URA3 inserted at the ura3 locus (GLC7-res).

To rule out the possibility that the poor growth of glc7E101Q observed on YPAG is the consequence of a petite phenotype resulting from mitochondrial mis-function, tetrad analysis was performed on diploid cells heterozygous for glc7-E101Q in a genetic background homozygous for a defective ade2 $\Delta-101$ gene. In the absence of adenine, ade2 $\Delta-101$ cells accumulate P-ribosylaminoimidazole, an intermediate of the adenine synthesis pathway. Mitochondrial oxidation of this intermediate results in a red pigment which colors colonies [41]. We observed glc7-E101Q spore colonies consist-
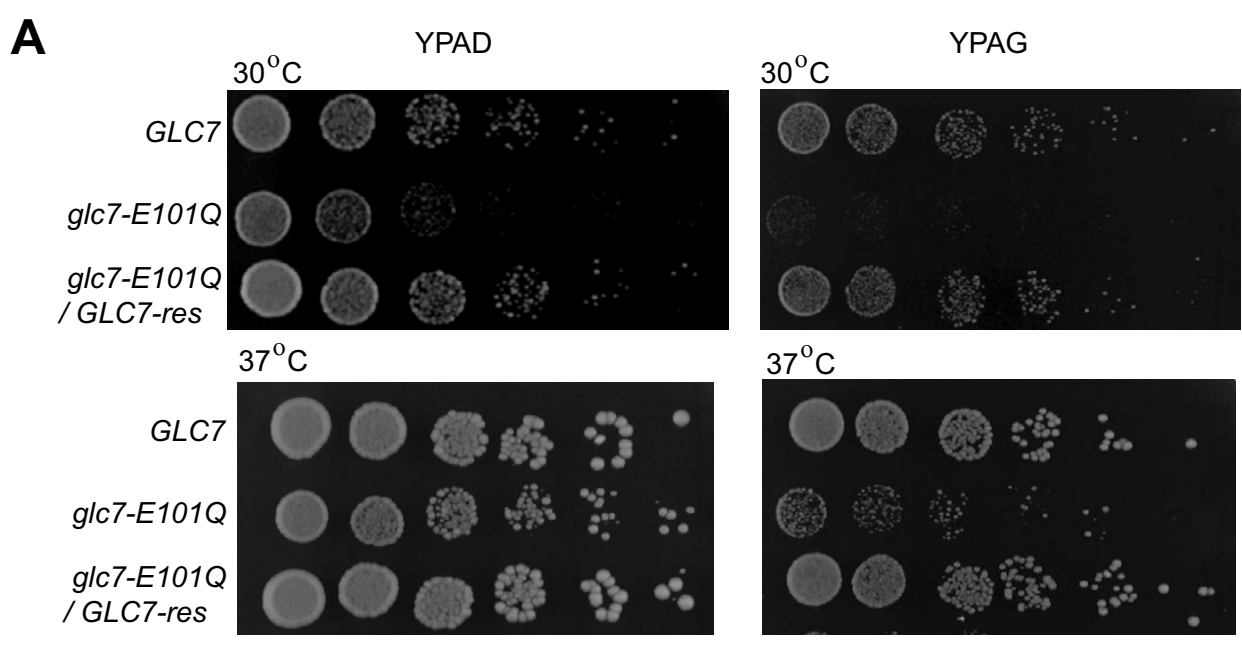

B

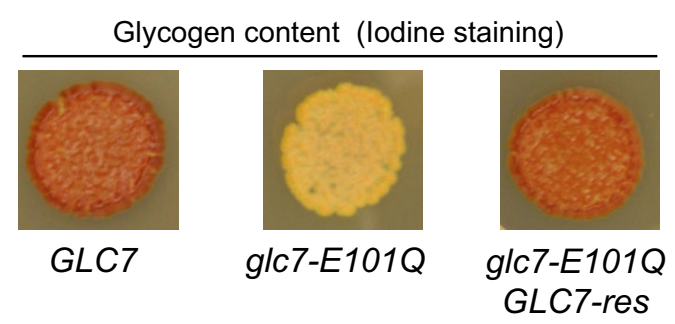

Figure 3

glc7-EIOIQ mutant is impaired in glucose metabolism. (A) Growth of wild type (GLC7), mutant (glc7-EIOIQ) and rescue (glc7-E I0IQ/GLC7-res) strains was examined by spotting assays (5-fold serial dilutions of I.0 $\left.\times 10^{6} \mathrm{cells} / \mathrm{ml} ; 5 \mu \mathrm{l} / \mathrm{spot}\right) \mathrm{grown}$ in YPAD or YPAG for $48 \mathrm{hr}$ at $30^{\circ} \mathrm{C}$ and $37^{\circ} \mathrm{C}$. (B) Glycogen content was assessed in wild type (GLC7), mutant (glC7-ElOIQ) and rescue (GLC7-res) strains by iodine staining. Brown color correlates with glycogen content. 
ently accumulated this red pigment on medium lacking adenine demonstrating the presence of functional mitochondria (data not shown). Taken together, these results support that the glc7-E101Q mutation is a stable recessive allele and exhibits impaired catalytic activity in vivo.

\section{SGA analysis of glc7-E I I I Q reveals a broad genetic network encompassing Glc7-regulated processes}

In order to expand the genetic network of Glc7 and to identify new candidate genes involved in Glc7-dependent processes, we screened $\sim 4,600$ non-essential genes for synthetic interactions with glc7-E101Q using the SGA methodology (Additional Files 3 and 4). Two-independent genome-wide screens revealed a total of 786 candidate synthetic sick/lethal (SSL) interactions (Additional File 4). To confirm SSL genes identified, we utilized a modified spot assay version of random spore analysis described previously [13]. Since Glc7 has been shown to regulate sporulation $[19,22,42]$ and meiosis $[43,44]$ we wished to rule out the possibility that genes identified as SSL with glc7E101Q may have resulted from meiotic and/or sporulation defects due to haploinsufficiency for GLC7. To circumvent this problem, random spore analysis was performed using a query strain of $g l c 7-E 101 Q$ that contained GLC7:URA3 under control of the endogenous GLC7 promoter inserted in the ura3 locus (GLC7-res) (see Methods and Additional File 3). Using this methodology, mating, sporulation and selection of MATa haploid progeny were performed under conditions in which wild type GLC7 was co-expressed in the glc7-E101Q mutant. Following the selection of MATa progeny, cells expressing wild type GLC7 were eliminated by plating on 5-fluoro-orotic acid (5-FOA) medium which prevents the growth of cells expressing a functional URA3 gene [45]. Plate scoring from the random spore analysis confirmed 245 genes as SSL with glc7-E101Q. The SSL genes were then grouped into functional classes according to their biological process GO (Gene Ontology) annotations deposited in the Saccharomyces Genome Database (GO-slim mapping table, downloaded on June $\left.4^{\text {th }}, 2008\right)$. Additional File 5 lists the 494 annotations encompassing 35 high-level GO terms for the 245 SSL genes. Using a hypergeometric distribution model [46], the frequency distribution of the GO terms identified for SSL genes was compared to those represented in the deletion array and examined for enrichment of particular biological processes (Figure 4 and Additional File 6). The set of SSL gene annotations was significantly enriched for 5 GO-terms: Organelle Organization and Biogenesis $(p<0.01)$; Protein modification process $(p<0.05)$; Anatomical Structure Morphogenesis $(p<0.05)$; Nuclear Organization $(p<0.01)$; and Biogenesis and Cell Budding $(p<0.05)$. Since Glc7 has been shown to play a role in all these processes, this suggests that the glc7-E101Q mutant is defective in multiple aspects of the Glc7 function.
To reveal the processes buffered by GLC7, 163 of 245 genes interacting with the glc7-E101Q mutant were manually grouped into 12 functional categories (Table 2 ). The majority of these genes are implicated in critical cellular processes such as chromosome segregation, nutrient-sensing, stress response and mitochondrial function. The information currently available on the remaining set of genes is too fragmental to allow classification in any of the listed categories (Additional File 5).

\section{Chromatin remodeling, chromosome segregation, DNA damage, cell polarity and cytokinesis genes}

A set of genes encoding histone-modifying proteins with a role in chromatin remodeling and transcription show SSL interaction with glc7-E101Q. This group includes the histone H3 acetyltransferase RTT109/KAT11, the histone H3 methylase DOT1/KMT4, the component of the Rpd3 histone deactylase PHO23, the subunit of the SAGA/SLIK complexes CHD1 involved in histone acetylation, the peptidyl-prolyl cis-trans isomerase FPR4 involved in histone $\mathrm{H} 3$ and $\mathrm{H} 4$ folding, the nucleosome remodeling factor ASF1, and the histone-associated factor UAF30. These results are in agreement with a previous observation that doc1 $\Delta$ glc7-127 double mutants exhibited a slow growth phenotype due to mis-regulation of histone H3 phosphorylation [47]. In addition, the loss of SET1, which encodes a histone methyltransferase, was also shown to cause lethality in glc7-127 cells [48]. Collectively, these findings indicate that correct histone modification is required for the survival of $g l c 7$ mutants.

Genes with a role in DNA damage included components of chromatin remodeling complexes (IES2 and RSC2), the checkpoint signaling gene, $M R C 1$, subunits of DNA-repair complexes (EXO1, LIF1, PMS1, RAD4,RAD14, TDP1 and UNG1) and DNA-damage responsive genes (LSM12, RFX1, YFR017C and YPR147C). This set of genes emphasizes the requirement for proper chromosome segregation in $g l c 7-E 101 Q$ cells and the critical role of the DNA-repair machinery during mitosis. Several other genes identified indicate that Glc7 plays a critical role in chromosome segregation and cytokinesis. Genes in these categories include regulators of microtubule dynamics (the microtubule +TIP protein BIM1, a-tubulin TUB3, and the Glc7 regulatory subunit $B U D 14)$ and the cytokinetic actomyosin ring (the formin BNR1, anillin-like protein BOI1, and two regulators of Rho1 GTPase ROM2 and BAG7 $[49,50])$. In addition, AXL2 and BUD4 were identified which share a physical interaction and are implicated in cell polarity and cell-cycle control [51]. Other genes involved in chromosome segregation included chromatid cohesion genes (CTF8 and REC8), the mini-chromosome maintenance gene, MCM22, cytokinesis genes (CIK1 and $K A R 3)$, components of the spindle checkpoint (BUB1, $B U B 3, M A D 1$ and $M A D 2)$, subunits of the nuclear pore 


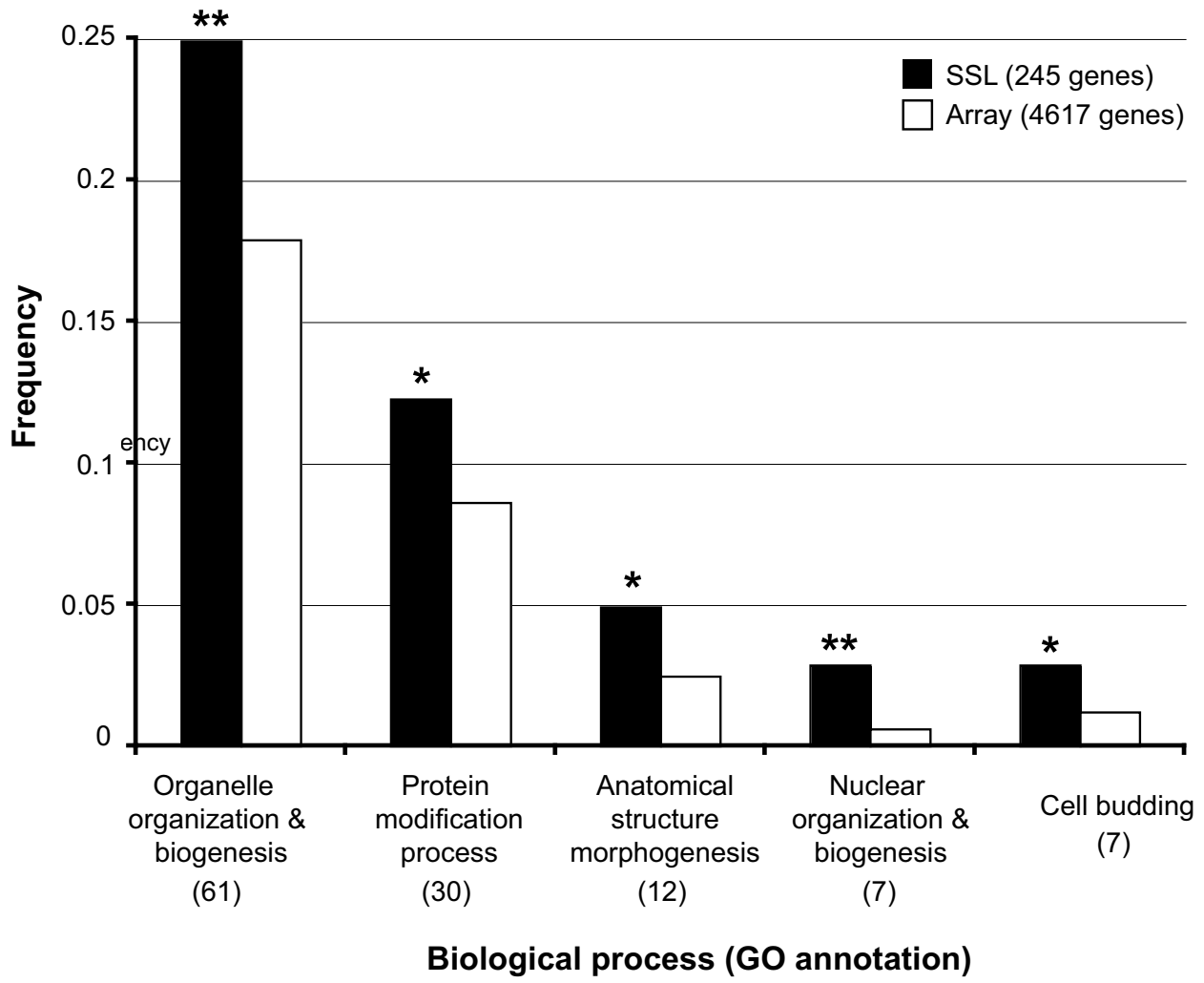

Figure 4

Biological processes overrepresented in glc7-EIOIQ SSL genes. Indicated are the frequencies of high-level GO terms represented in the set of SSL genes (closed bars) that were significantly enriched $(p<0.0 \mathrm{I}, * * ; p<0.05, *)$ when compared to those represented in the set of array genes (open bars). The number of genes identified in each GO process is shown in parentheses.

complex (NUP53, NUP84 and NUP133) and karyopherin genes (KAP120 and SXM1). The identification of a widespanning range of genes involved in chromosome segregation supports that Glc7 plays a prominent role in buffering against chromosome mis-segregation. This is supported by previous findings that loss of BUD14 [52] or mutation of the kinetochore protein, DAM1, [53] caused lethality of conditional $g l c 7$ mutants. Furthermore, other data supports that Glc7 plays a key role in regulating the attachment of kinetochore microtubules to chromosomes. It is postulated that this regulation occurs via Glc7dependent de-phosphorylation of kinetochore-localized proteins, such as Ndc10 and other yet to be identified substrates $[29,30,32]$.

Nutrient-sensing, stress response and mitochondrial genes In accordance with Glc7's prominent metabolic role, particularly glycogen accumulation and glucose repression, several genes involved in nutrient sensing, metabolism and stress response were identified. SIP5 and the Snf1activating kinase $S A K 1$, which are both involved in the regulation of Snf1 kinase, were required for growth of
glc7-E101Q. Sip5 physically interacts with both Reg1-Glc7 and Snf1, and is thought to regulate the interaction between Glc7 and Snf1 [39]. Other nutrient sensing genes included GPH1 (glycogen phosphorylase), TDH3 (glyceraldehyde-3-phosphate dehydrogenase), GPA2 (a-subunit of the glucose sensor G-protein), TPK1 (cAMP-dependent kinase involved in the Ras-cAMP signaling pathway), SSK1 (HOG pathway kinase), CKB1 and CKB2 ( $\beta$-and $\beta^{\prime}-$ casein kinase subunits) and various transport proteins (BAP2, HXT17, MCH4, YBR235W and YJL193W). Genes required for growth under stress conditions (ATG5, ATG15, HIT1, MCA1, NST1, NVJ1, ORM2, SFL1, SPG5, UGA1, URM1, VAC8, WHI2 and YNR029C) are also in this group. These findings indicate that nutrient sensing and stress signaling pathways are required for the growth of the glc7-E101Q mutant. This group of interactions can be related to a previous observation that mutation of $R H R 2$, encoding the DL-glycerol-3-phosphatase, is lethal when introduced in a glc7-Y170 background [54]. In addition, epistasis and transcriptional analyses have shown a role for Bud14-Glc7 in the regulation of Msn2, a transcrip- 
tion factor controlling the expression of stress-response element (STRE)-genes [55].

Genes with a role in mitochondrial activity and inheritance included subunits of the ATP synthase (ATP4 and ATP12), genes required for cytochrome-c oxidase function (COX19, CYC7 and SCO1), genes involved in mitochondrial replication (RIM1)-transcription (HAP2, MTF1 and PET122) and -translation (MSK1, RML2 and RSM18), genes required for mitochondrial homeostasis/metabolism (CBR1, MIR1, MRS4 and PDX1) and genes with a role in mitochondrial morphology and distribution (IMP1, MDM34 and YPT11). This group also contains genes that localize to the mitochondria (FMP42, PUT2, VPS73, YBL095W, YGL059W, YGR021W, YGR287C, YHR161W, YJR039W and YNL320W) and may be required for optimal mitochondrial function. Thus, mitochondrial function is essential when PP1 function is compromised.

\section{Transcription, protein synthesis and protein regulation genes}

Genes involved in transcription included transcription factors (CAF120, DAT1,DST1, HMS2, and SUM1), elongator complex components (ELP2 and KTI12), mediator complex components (NUT1, SSN2 and SSN8), a transcription termination factor (RTT103) and RNA processing factors (CDC40 and LSM6). Protein synthesis genes included components of the large ribosomal subunit (RPL6B, RPL12A, RPL19A, RPL24A and RPL37), components of the small ribosomal subunit (RPS1A, RPS16A, RPS19A and RPS25A) and YBL054W, which is putatively involved in rRNA synthesis. Other genes were identified with various roles in protein modification such as protein glycosylation (KTR1, KTR3, KTR4 and PMT5), ubiquitinregulated protein degradation (NPL4, OTU1, SLX8, UMP1 and USA1) and protein phosphorylation (PPZ1, PPM1 and RTS3). All these genes likely play a role in the expression of and/or the modification/turnover gene products essential for processes buffered by Glc7.

The synthetic lethal interaction of $g l c 7-E 101 Q$ with the PPZ1 phosphatase and two PP2A subunits (PPM1 and RTS3) suggests an interplay between these phosphatases. Few synthetic lethal interactions are currently available for PPZ1, PPM1 and RTS3. However, it was interesting to note that $g l c 7-E 101 Q$ and PPZ1 share synthetic lethal interactions with both BIM1 and BUB3. In addition, it has been previously suggested that an exchange of regulatory subunits between Glc7 and PPZ phosphatase may be the basis for the observed synthetic lethal interaction of $g l c 8$ with $g l c 7$ mutants and $p p z 1 p p z 2$ [56]. These observations support that signaling cross-talk occurs between these phosphatases.
Vesicle transport, lipid metabolism and S-adenosylmethionine synthesis genes

Genes with a role in vesicle transport included ARF1 (coat formation small GTPase), BTS1 (geranygeranyl diphosphate synthase required for the interaction of small GTPases with vesicle/organelle membranes), regulators of Golgi vesicle targeting and fusion (COG complex subunit COG5, the TRAPP subunit GSG1, and the Ypt1 GTPase Activating Protein, GYP8) and regulatory proteins involved in endocytosis (actin cytoskeleton regulator, END3, phosphoinositide-binding protein, ENT5, and the coat regulators, MST27 and UBP3). These interactions may indicate a requirement for the transport of specific cargo(s) in the glc7-E101Q mutant that are required for viability. Alternatively, they may reflect a more direct role for Glc7 in the regulation of vesicle transport. This is supported by previous studies that indicate a regulatory function for Glc7 on components of vesicle trafficking. For example, Glc7 and its targeting subunit, Scd5, were shown to regulate Pan1, an actin regulatory protein involved in endocytosis. Interestingly, both Pan 1 and End3 (identified in our SGA analysis) exhibited physical interactions with Scd5, implicating them in Glc7 recruitment to sites of endocytosis [57]. In addition, a separate study demonstrated a role for Glc7 in the regulation of SNARE protein complexes that are required for vesicle-membrane fusion [58].

Lipid metabolism genes identified included those functioning in ergosterol metabolism (ERG5 and OSH3), fatty acid metabolism (ANT1 and PCS60), phospholipid metabolism (OPI3, PLB1, PSD1 and SCS3) and a set of genes for peroxisomal proteins (PEX6, PEX29 and PEX31). The intimate synthetic lethal relationships between lipid metabolism, mitochondrial function and vesicle transport genes is probably the basis for this set of SSL interactions.

Genes involved in S-adenosylmethionine (SAM) -dependent processes included methyltransferases (BUD23, NCL1, RMT2 and TRM1) and the SAM decarboxylase SPE2. The deletion of these genes likely impacts on SAM pool and this, in turn, affects Glc7-dependent processes that utilize this co-factor such as histone methylation, ergosterol synthesis and phospholipid synthesis.

\section{Network analysis of the GIc7 interacting genes}

We performed a network analysis of the glc7-E101Q SSL genes by examining protein-protein and genetic interactions available from the BioGRID database (version 2.0.41, released on June 1, 2008 [26]). This analysis revealed 95 genes that are interconnected through 99 and 212 protein-protein and genetic interactions, respectively. Based on protein-protein interactions, we identified 23 distinct molecular modules involving 72 GLC7 genetic interactors (Figure 5). These modules are components of 
molecular machines involved in microtubule-based polarity, the spindle checkpoint, chromatin remodeling and transcription, translation, regulation of casein kinase 2 , regulation of the V-ATPase, nuclear pore complex and nucleo-vacuolar transport. Some modules are interconnected by genetic interactions among their components (Figure 5, red edges). For example, components of the "microtubule-based polarity", the "spindle checkpoint" and the "nuclear pore complex" modules show genetic interactions. This reflects how these modules cooperate during mitosis. In some cases, two modules are connected by genetic interaction with a gene that is not part of any module. For example, CTF8 and SLX8, both playing a role in the control of DNA replication, connect via genetic

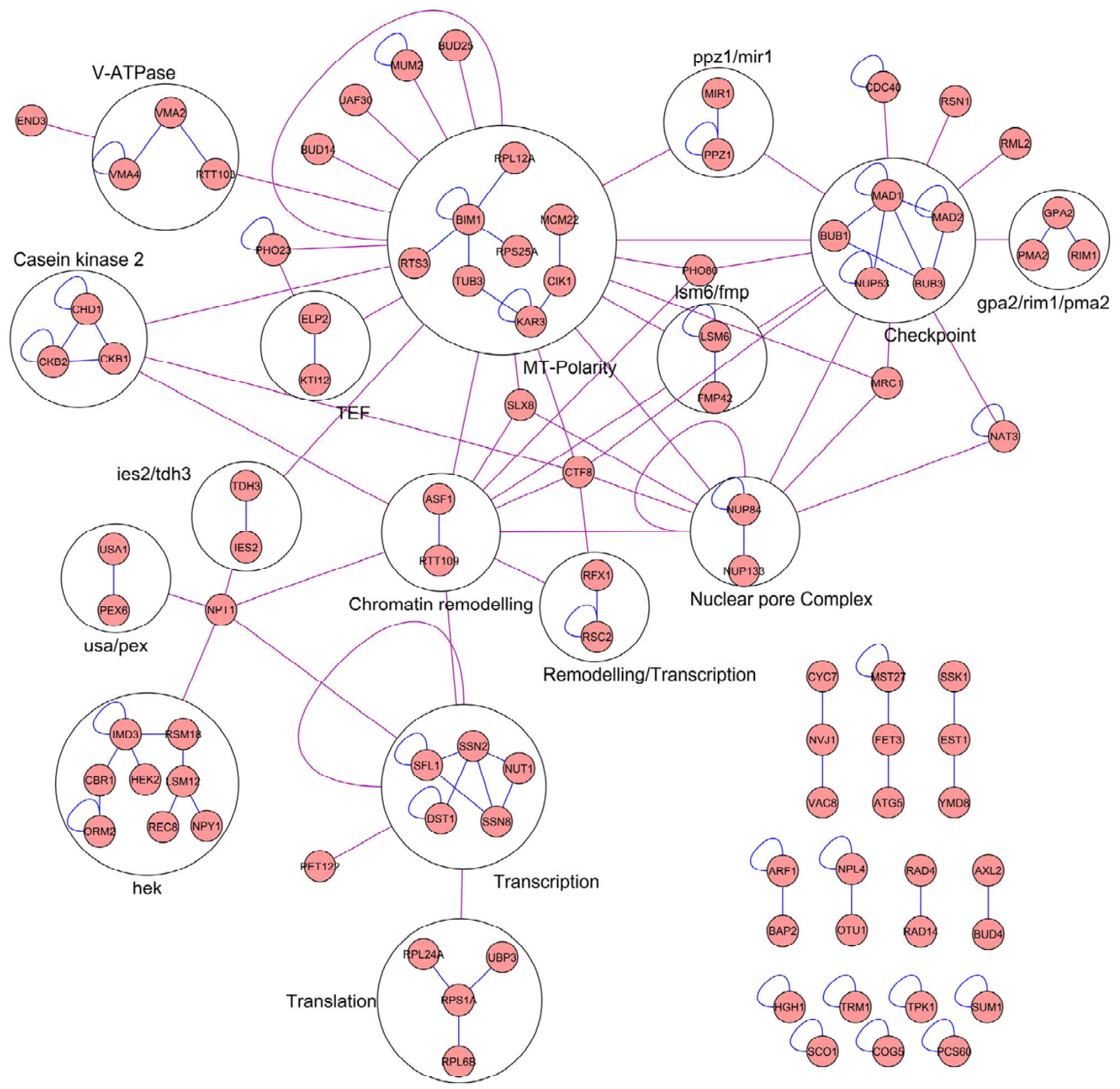

Figure 5

A network of protein-protein and genetic interactions among glc7-EIOIQ SSL genes. Genes showing SSL interaction with glc7-EIOIQ (nodes) were grouped in modules based on their physical interaction profiles (blue edges). The genetic interactions interconnecting modules or connecting modules and single nodes are depicted as red edges. 
interactions to the "microtubule-base polarity", "nuclear pore complex" and "remodeling/transcription" modules. Finally, some modules, such as "NPL4-OTU1" (whose products are involved in polyubquitin-mediated protein degradation) and "AXL2-BUD4", are not connected to any other module. This probably reflects that the map for genetic interactions is still incomplete and that some genes showing SSL interaction with glc7-E101Q have not yet been screened by the SGA. Additional SGA screens will be required to obtain a comprehensive interaction profile for these genes.

\section{Discussion}

A number of studies support that Glc7 plays a critical role in the regulation of several cellular processes such as cell polarity, chromosome segregation, cytokinesis, and cell cycle control [1-4]. However, the precise role of Glc7 in the majority of these processes and the identity of Glc7 substrates involved in the regulation of these events remains poorly understood. The lack of information regarding Glc7's signaling network is due, in part, to a large disconnect between genetic and proteomic data available. Currently, the number of protein-protein interactions reported greatly exceeds genetic interactions $[26,59,60]$. The genetic interaction space, however, is much more dense than the physical interaction network, and the number of SSL combinations for a given gene is estimated to be 4-times that of protein-protein interactions [13]. The high number of physical interactions and diverse phenotypes of conditional $g l c 7$ mutants suggest Glc7 has a large and complex SSL interaction network.

In order to expand the genetic interaction data set for Glc7, we examined a novel catalytic mutant, glc7-E101Q, for synthetic lethal interactions using SGA. Existing conditional $g l c 7$ alleles contain mutations outside of the Glc7 catalytic domain that can alter the binding of regulatory subunits $[1,18,19,22,25]$, potentially resulting in allelespecific genetic interaction patterns. To achieve our goal to globally map the GLC7 genetic interactions, a hypomorphic $g l c 7$ allele was constructed. Based on 3-dimensional modeling and previous structure-function studies, the SGA query mutant glc7-E101Q was predicted to exhibit reduced catalytic efficiency while maintaining structural similarity to wild type GLC7. That two iron transporter genes (FET3 and MRS4), were found in our SGA analysis suggested that a normal iron supply is important for the normal growth of the glc7-E101Q mutant, and is consistent with the idea that this allele is catalytically compromised due to altered metal cofactor binding. Furthermore, phenotypic analyses indicated $g l c 7$ E101Q is a stable recessive hypomorphic allele. Similar to some conditional glc7 mutants, glc7-E101Q cells exhibited impaired growth in glucose-limited medium and defects in glycogen accumulation $[16,22,36]$. However, in contrast to other $g l c 7$ mutants that have been shown to have chromosome mis-segregation and cell cycle progression defects (e.g.: glc7-10 [1,32], glc7-129 [29] and glc7$Y 170[31])$, glc7-E101Q cells had no appreciable cell cycle delay or chromosome loss. These observations suggest a threshold effect may occur in $g l c 7-E 101 Q$ cells, such that weakened catalytic efficiency of Glc7 is tolerated and/or compensated at differing levels depending on the cellular process and the demand for Glc7 activity.

SGA analysis of glc7-E101Q resulted in a large number (786) of SSL hits in two separate screens. We expect that the large number of genes identified be due, at least in part, to the haploinsufficiency observed for glc7-E101Q mutants, which resulted in reduced spore viability and placed constraints on colony scoring. To solve this problem and generate a high confidence dataset, we modified the confirmation procedure by creating a second query strain that expressed a selectable copy of wild type GLC7 (GLC7-res). Sporulation, meiosis and growth of haploid progeny were performed in $g l c 7-E 101 Q$ cells expressing wild type GLC7 inserted at the URA3 locus. Pinning on counter-selective medium then eliminated haploid cells expressing the wild type GLC7 allele. Using this strategy, false positive hits were rejected and 245 hits were confirmed as true SSL interactions. We anticipate this strategy may be applicable to confirm SGA screens of other query genes that interfere with sporulation or spore germination.

Genes showing synthetic sick/lethal interactions with glc7-E101Q were grouped in 12 functional classes. Although only one (BUD14) of 7 previously reported SSL interactions (BUD14, DAM1, DOC1, GLC8, RHR2, SET1 and SLT2) for GLC7 was identified in our analysis, a number of established Glc7-mediated processes were captured in our screen. In particular, sets of genes fall into functional classes encompassing the 7 previously reported GLC7 SSL interactions, which are chromatin remodeling, chromosome segregation/cytokinesis, and nutrient sensing/metabolism. In addition, certain SSL genes identified highlight events that appear to be directly regulated by Glc7. These include genes involved in glucose repression (SIP5) [39], chromosome segregation (BUD14) [18] and endocytosis (END3) [57]. Lastly, our SGA analysis of glc7E101Q provides a rich data set of genetic interactions that expands on previously known Glc7-regulated processes, and the glc7-E101Q synthetic interaction pattern reveals new facets of Glc7 function. For example, the requirement for mitochondrial and phospholipid metabolism genes when Glc7 function is compromised suggests a role for Glc7 in these processes. 


\section{Conclusion}

To uncover the genetic interaction network of the essential PP1 gene GLC7, a novel catalytic mutant allele, glc7E101Q, was used in an unbiased genome-wide screen for SSL interactions. We found 245 genes whose deletion was detrimental for the growth of glc7-E101Q. Functional grouping of these genes and analysis of their physical and genetic interaction expand the genetic network of established Glc7-regulated processes and suggest novel regulatory roles for Glc7.

\section{Methods}

\section{Media, growth conditions and strain manipulations}

Yeast strains (Table 1) were created through PCR-based transformation $[61,62]$. Media (rich media: YPAD and YPD (2\% glucose), YPAG (3\% glycerol with $0.08 \%$ glucose); synthetic media: SC and SD) were prepared as previously described [63]. Standard methods for culture of yeast strains and integrative transformation, mating, sporulation and tetrad analysis was performed as previously described [63]. SGA analysis was performed in strains derived from the S288C diploid BY4743 [64]. All other analyses were performed in strains derived from the S288C diploid Y270 [65].

\section{Mutagenesis of Glc7 and strain construction}

A $1.2 \mathrm{~kb}$ PCR product containing 3' sequence of the GLC7 ORF was cloned into pBSK using KpnI and NotI to create pGLC7-1. The KANMX4 selection cassette was amplified by PCR from pFA6A-KANMX4, digested with NotI and SacI and cloned into pGLC7-1, creating pGLC7-KANMX4. This construct was used as a template for PCR-based mutagenesis of the catalytic domain at codon 273 (D91N: GAT to AAT) and codon 303 (E101Q: GAG to CAG). A silent restriction site (AvrII in D91N and HindIII in E101Q) was introduced into the mutagenic 5' primer to mark the mutation. Mutagenic PCR products were transformed into Y270 as previously described [65], and G418resistant transformants selected for on YPAD containing $200 \mu \mathrm{g} / \mathrm{ml} \mathrm{G418} \mathrm{(GIBCO).} \mathrm{Integration} \mathrm{into} \mathrm{the} \mathrm{GLC7}$ locus was confirmed by amplification of a PCR product that spanned the ORF and the KANMX4 cassette and by restriction digest with AvrII or HindIII. Finally, the presence of a single point mutation (D91N or E101Q) in the ORF and no others was confirmed by sequencing. Diploid strains heterozygous for D91N (YNS19) and E101Q (YNS53) mutations were sporulated, and haploid glc7E101Q:KANMX4 MATa and MATa segregants (YNS91, YNS90) isolated for phenotypic analyses. A similar cloning strategy was used to create ProA fusions of both wild type GLC7 and glc7-E101Q. A Glc7 PCR product lacking the endogenous stop codon was cloned into pBSK (pGLC7-2) and the ProA and KANMX4 selectable markers from pFA6A-ProA-KANMX4 [66] integrated using NotI and SacI, creating pGLC7-ProA. This construct was used for PCR directed mutagenesis and transformation into Y270 as described above, sporulated and haploid segregants (YNS26, YNS27) isolated for the analysis of protein stability. Wild type GLC7-proA strains were derived in a similar manner (YNS23, YNS44).

For $g l c 7-E 101 Q$ rescue experiments, a GLC7 was cloned into the integrative plasmid pRS306 by first amplifying a PCR product from genomic DNA that contained the entire GLC7 ORF and $0.5 \mathrm{~kb} 5$ ' promoter sequence and $0.3 \mathrm{~kb} 3$ ' UTR, digested with KpnI and SacI and ligated into pRS306 [67], resulting in pGLC7-3. pGLC7-3 was linearized with StuI, and transformed into the ura3 locus of the heterozygous diploid strain YNS53. Integration at the ura3 locus resulted in wild type copy of GLC7 marked with URA3 (GLC7-res; strains YNS138, YNS141) on the opposite arm (116167-116970) of chromosome V relative to the GLC7 locus (432491-433954). In 40 meiotic events GLC7-res segregated as an un-linked gene (28TT : 3NPD : 9PD) independently of GLC7 and glc7-E101Q.

To create the SGA query strain, YNS98, a NATMX4 PCR product with homology to the GLC7 3' UTR sequences was amplified by PCR from p4339 [12], and used to replace the KANMX4 cassette in YNS90. Genomic DNA of the resulting strain was then used to amplify a PCR product containing the E101Q mutation and the NATMX4 cassette. This PCR product was transformed into Y5563 according to previously described methods [13]. To create the query strain for random spore analysis (YNS100), a MATa glc7-E101Q:NATMX4/GLC7-res strain was first isolated by tetrad dissection from a heterozygous diploid (YNS99 $\times$ YNS98) and then backcrossed to Y5663.

\section{Growth assays, FACS and glycogen staining}

To assess cell growth, wild type (YNS3) and glc7-E101Q (YNS91) and GLC7-res (YNS138) strains were grown to mid-log phase in YPAD, diluted to $5.5 \times 10^{5}$ cells $/ \mathrm{ml}$ ( 0.05 OD units) and incubated at $30^{\circ} \mathrm{C}$ for a total of 7 hours. Cells were collected at 1-hour intervals, and cell density determined using a hemocytometer. For spotting assays, log phase cells grown in liquid YPAD were diluted to $1.0 \times 10^{6}$ cells/ml ( $0.1 \mathrm{OD}$ units) and 5-fold serial dilutions spotted ( $5 \mu \mathrm{l} / \mathrm{spot})$ to YPAD or YPAG plates and incubated for $2-3$ days at $18^{\circ} \mathrm{C}, 25^{\circ} \mathrm{C}, 30^{\circ} \mathrm{C}$ and $37^{\circ} \mathrm{C}$. To determine benomyl-sensitivity, cells were examined in parallel with benomyl-sensitive (tub1-1) and resistant (tub2-104) strains [68,69] on $10 \mu \mathrm{g} / \mathrm{ml}$ benomyl or DMSO plates incubated for $2-3$ days at $30^{\circ} \mathrm{C}$. Cell cycle progression of wild type and glc7-E101Q strains was determined by FACS analysis as previously described [70]. Fixed cells from the FACS analysis were also used for bud index scoring, and the proportion of un-budded, smallbudded (bud $<50 \%$ mother cell) and large-budded cells determined. Cells were pre-treated with Zymolase $(20 \mu \mathrm{g} /$ 
Table I: Yeast strains used in this study

\begin{tabular}{|c|c|c|}
\hline Strain & Genotype & Source \\
\hline BY4743 & $\begin{array}{l}\text { MATal } \alpha \text { ura3 } 30 / \text { ura } 3 \Delta 0 \text { leu2 } \Delta 0 / \text { leu } 2 \Delta 0 \text { his } 3 \Delta l / \text { his } 3 \Delta l \\
\text { LYS2/lys } 2 \Delta 0 \text { met } / 5 \Delta 0 / M E T I 5\end{array}$ & {$[64]$} \\
\hline Y270 & $\begin{array}{l}\text { MATa/MAT } \alpha \text { ura3-52/ura3-52 lys2-80I/lys2-80I ade2-10II } \\
\text { ade2-10I trpI } \Delta I / \operatorname{trp} I \Delta \text { his3 } 4200 / \text { his3 } \Delta 200\end{array}$ & {$[65]$} \\
\hline Y5563 & MATa can I $\triangle:: M F A I p r-H I S 3$ lyp I $\Delta$ his $3 \Delta I$ leu $2 \Delta 0$ ura $3 \Delta 0$ met $15 \Delta 0$ & C Boone \\
\hline$\triangle$ ArrayORF & MATa orf $\Delta:: K a n M X 4$ LYS2 his $3 \Delta I$ leu $2 \Delta 0$ met $15 \Delta 0$ ura $3 \Delta 0$ & {$[7 \mid]$} \\
\hline YNS2 & MAT $\alpha$ ura3-52 lys2-80I ade2-10I trpl $\Delta I$ his $3 \Delta 200$ & This study \\
\hline YNS3 & MATa ura3-52 lys2-80I ade2-10I trpl $\Delta I$ his $3 \Delta 200$ & This study \\
\hline YNSI9 & $\begin{array}{l}\text { MATalMAT } \alpha \text { glc7-D9IN:KanMX4/GLC7 ura3-52/ura3-52 } \\
\text { lys2-80I/lys2-80I ade2-10I/ade2-10I trpI } \Delta 1 / \text { trpI } \Delta I \\
\text { his3 } 3200 / \text { his3 } 3200\end{array}$ & This study \\
\hline YNS23 & $\begin{array}{l}\text { MATa GLC7:ProA:KanMX4 ura3-52 lys2-80I ade2-10I } \\
\text { trp I } \Delta \text { I his } 34200\end{array}$ & This study \\
\hline YNS26 & $\begin{array}{l}\text { MAT } \alpha \text { glc7-EIOIQ:ProA:KanMX4 ura3-52 lys2-80I ade2-10I } \\
\text { trpI } \Delta \text { I his3 } 4200\end{array}$ & This study \\
\hline YNS27 & $\begin{array}{l}\text { MATa glc7-EIOIQ:ProA:KanMX4 ura3-52 lys2-80I ade2-10I } \\
\text { trpI II his3 } 4200\end{array}$ & This study \\
\hline YNS44 & $\begin{array}{l}\text { MAT } \alpha \text { GLC7:ProA:KanMX4 ura3-52 } \\
\text { lys2-80I ade2-101 }\end{array}$ & This study \\
\hline YNS53 & 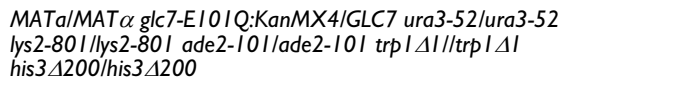 & This study \\
\hline YNS90 & $\begin{array}{l}\text { MAT } \alpha \text { glc7-EIOIQ:kanMX4 ura3-52 lys2-80I ade2-10I trpl } \Delta I \\
\text { his3 } 4200\end{array}$ & This study \\
\hline YNS91 & $\begin{array}{l}\text { MATa glc7-EIOIQ:KanMX4 ura3-52 lys2-80I ade2-I0I } \\
\text { trpI II his3 } 4200\end{array}$ & This study \\
\hline YNS98 & $\begin{array}{l}\text { MAT } \alpha \text { glc7-EIOIQ:NatMX4 can I } \Delta:: M F A I p r-H I S 3 \text { lypI } \Delta \\
\text { his } 3 \Delta I \text { leu2 } \Delta 0 \text { ura3 } \Delta 0 \text { met I } 5 \Delta 0\end{array}$ & This study \\
\hline YNS99 & MATa ura3-52::GLC7:URA3 lys2-80I ade2-I0I trpl $\Delta I$ his3 $\Delta 200$ & This study \\
\hline YNSIO0 & $\begin{array}{l}\text { MAT } \alpha \text { glc7-EIOIQ:NatMX4 ura3-52::GLC7:URA3 } \\
\text { can I } \Delta:: M F A I \text { pr-HIS3 lypI } \Delta \text { his } 3 \Delta I \text { leu2 } \Delta 0 \text { ura } 3 \Delta 0 \text { met I } 5 \Delta 0\end{array}$ & This study \\
\hline YNSIOI & $\begin{array}{l}\text { MATa his3-II, I 5::GFP:Lacl:HIS3 lacO:URA3, } \\
\text { SPC29:CFP:kanMX4 lys2-80I ade2-IOI trpI } \Delta \text { I }\end{array}$ & This study \\
\hline YNSI02 & $\begin{array}{l}\text { MATa glc7-EI0IQ:kanMX4 his3-I I, I 5::GFP:Lacl:HIS3 } \\
\text { lacO:URA SPC29:CFP:kanMX4 lys2-80I ade2-I0I trpI } \Delta \text { I }\end{array}$ & This study \\
\hline YNSI 28 & $\begin{array}{l}\text { MATaIMAT } \alpha \text { glc7-EI OIQ:KanMX4/GLC7 ura3-52/ ura3-52: } \\
\text { :GLC7:URA3 lys2-80I/lys2-80I ade-I0I/ade2-I0I trpI } \Delta \text { I/trpI II } \\
\text { his3 } 4200 / \text { his3 } 3200\end{array}$ & This study \\
\hline YNSI38 & $\begin{array}{l}\text { MATa glc7-EI0IQ:KanMX4 ura3-52::GLC7::URA3 lys2-80I ade2-10I } \\
\text { trpI II his3 } 4200\end{array}$ & This study \\
\hline YNSI4I & $\begin{array}{l}\text { MAT } \alpha \text { glc7-EI0IQ:KanMX4 ura3-52::GLC7::URA3 lys2-80I ade2-10I } \\
\text { trp I } \Delta I \text { his3 } 4200\end{array}$ & This study \\
\hline
\end{tabular}


Table 2: Functional processes of 163 genes showing SSL interactions with glc7-EIOIQ

\begin{tabular}{|c|c|}
\hline Functional category & Genes \\
\hline Cell polarity & $A X L 2, B U D 4$ \\
\hline Chromosome segregation & $\begin{array}{l}\text { BAG7, BIMI, BNRI, BOI2, BUBI, BUB3, BUDI 4, CIKI, CTF8, KAPI20, KAR3, MADI, MAD2, MCM22, NUP53, } \\
\text { NUP84, NUPI33, REC8, ROM2, SXMI, TUB3 }\end{array}$ \\
\hline DNA damage & EXOI, IES2, LIFI, LSMI2, MRCI, PMSI, RAD4, RADI4, RFXI, RSC2, TDPI, UNGI, YFROI 7C, YPRI I7C \\
\hline Histone modification & ASFI, CHDI, DOTI, FPR4, PHO23, RTTI09, UAF30 \\
\hline Lipid metabolism & ANTI, BUD25, ERG5, OPI3, OSH3, PCS60, PEX6, PEX29, PEX3I, PLBI, PSDI, SCS3 \\
\hline Mitochondrial function & $\begin{array}{l}\text { ATP4, ATPI 2, CBRI, COXI9, CYC7, FMP42, HAP2, IMPI, MDM34, MIRI, MRS4, MSKI, MTFI, PDXI, PETI22, } \\
\text { PUT2, RIMI, RML2, RSMI8, SCOI, VPS73, YPTII, YBL095W, YGL059W, YGR02IW, YGR287C, YHRI62W, } \\
\text { YJR039W, YNL320W }\end{array}$ \\
\hline Nutrient sensing and stress signaling & $\begin{array}{l}\text { ATG5, ATGI5, BAP2, CKBI, CKB2, GPA2, GPHI, HITI, HXTI 7, MCAI, MCH4, NSTI, NVJI, ORM2, SAKI, SFLI, } \\
\text { SIP5, SPG5, SSKI, TDH3, TPKI, UGAI, URMI, VAC8, WHI2, YBR235W, YJLI93W, YNRO29C }\end{array}$ \\
\hline Phosphatase genes & PPMI, PPZI, RTS3 \\
\hline Protein modification and degradation & KTRI, KTR3, KTR4, NAT3, NPL4, OTUI, PMT5, SLX8, UMPI, USAI \\
\hline Protein synthesis & RPL6B, RPLI2A, RPLI9A, RPL24A, RPL37A, RPSIA, RPSI6A, RPSI9A, RPS25A, YBL054W \\
\hline SAM(I) synthesis & BUD23, NCLI, RMT2, SPE2, TRMI \\
\hline Transcription & CAFI 20, CDC40, DATI, DSTI, ELP2, HMS2, KTII2, LSM6, NUTI, RTTI03, SSN2, SSN8, SUMI \\
\hline Vesicular transport & ARFI, BTSI, COG5, END3, ENT5, GSGI, GYP8, MST27, UBP3 \\
\hline
\end{tabular}

(I): S-adenosylmethionine

$\mathrm{ml})$ to complete cell separation. Glycogen staining was performed as previously described [40]. Briefly, after 2day incubation at $30^{\circ} \mathrm{C}$, plates were exposed to iodine crystals (Sigma) for 1 minute, removed for $15 \mathrm{sec}$ and exposed again for $2 \mathrm{~min}$. Digital images were captured immediately after exposure to iodine.

\section{Analysis of chromosome segregation Microscopy}

MATa wild type (YNS101) and glc7-E101Q mutant (YNS102) strains that expressed Spc29-CFP (SPB marker), GFP-LacI and centromeric (CEN15) lacO repeats [34] were isolated from heterozygous diploids. Cells were incubated in $5 \mu \mathrm{g} / \mathrm{ml}$ a-factor for $3 \mathrm{hrs}$ at $30^{\circ} \mathrm{C}$, washed and released in YPAD and collected every $10 \mathrm{~min}(80 \mathrm{~min}$ total). Samples were fixed for $5 \mathrm{~min}$ in $4 \%$ formaldehyde, washed three times in PBS and imaged using a Nikon TE200 inverted microscope equipped with a $100 \times 1.4 \mathrm{NA}$ objective mounted on PE piezo z-drive/Improvision Orbit controller and Hammamatsu ORCA-ERG camera. Image stacks (0.5 $\mu \mathrm{m}$ sections, 10-12/image) were acquired using Volocity 4.0 and image deconvolution with Volocity 4.0 Restoration.

\section{Sectoring assay}

MATa wild type (YNS3), glc7-E101Q (YNS91) and ame1-6 (positive control for chromosome loss; Vogel unpublished data) strains lacking a functional ADE2 gene (ade2A-101) were transformed with a circular fragment of chromosome III encoding SUP11 (Circle III/SUP11) [35] and incubated for 4 days on YPD at $30^{\circ} \mathrm{C}$. SUP11 suppresses the ade2 $\Delta-101$ mutation resulting in the formation of white colonies. Loss of the CircleIII/SUP11 (an indicator of chromsome mis-segregation) was identified by the restoration of the ade2A-101 mutant phenotype causing the accumulation of P-ribosylaminoimidazole, a red colored pigment [41].

\section{Synthetic genetic array (SGA) analysis of glc7-E I 0 I Q}

Two-independent SGA screens were performed in triplicate using the ordered deletion array and Virtek pinning robot system as previously described $[12,13,71]$. The sizes 
of the resulting colonies were measured from digital images of the plates. A comparative set of mutant measurements relative to wild type control measurements enabled t-statistics and p-values to be calculated [13]. Double mutants that showed significantly reduced colony sizes ( $p$ $<0.05)$ were scored as hits. Hits identified in the SGA screens were evaluated by a modified spot assay version of random spore analysis [13] using a glc7-E101Q strain that co-expressed GLC7-res (YNS100) (Additional File 3) and finally scored as synthetic sick/lethal (SSL) or rejected as false positive. Spores were initially grown for 2 days at $30^{\circ} \mathrm{C}$ on solid haploid selection medium [synthetic dextrose $(\mathrm{SD})$ medium lacking histidine and arginine but containing canavanine: SD - His/Arg + canavanine]. MATa spore progeny were transferred to solid 5-fluoro-orotic acid (5-FOA) medium [45] and incubated at $30^{\circ} \mathrm{C}$ for 2 days to eliminate cells expressing GLC7-res. Cells were inoculated to microtiter plates in $250 \mu \mathrm{l}$ of liquid SD His/Arg + canavanine for 2 days at $30^{\circ} \mathrm{C}$. A Biomek FX robot (Beckman Coulter, Inc; CIAN robotics facility, McGill University) was used to perform serial dilutions and spotting to four different solid medium plates: SD/ MSG (monosodium glutamic acid) - His/Arg + canavanine/nourseothricin, SD/MSG - His/Arg + canavanine/ G418, SD/MSG - His/Arg +canavanine/nourseothricin/ G418, and SD/MSG - His/Arg/Ura + canavanine. Colony growth was scored following incubation for 2 days at $30^{\circ} \mathrm{C}$.

\section{Protein extraction, ID and 2D-SDS-PAGE}

All steps were performed at $4{ }^{\circ} \mathrm{C}$ unless otherwise indicated. Log phase yeast cultures were harvested and washed in PGSK+ buffer (PGSK': $50 \mathrm{mM} \mathrm{NaPO} 4,50 \mathrm{mM} \mathrm{NaCl}, 5$ $\mathrm{mM} \mathrm{KCl}, 60 \mathrm{mM}$ glucose, 4\% CHAPS, $50 \mathrm{mM}$ DTT, $5 \mu \mathrm{M}$ yeast protease inhibitors [Sigma P8215], $5 \mu \mathrm{M}$ PMSF, 5 $\mu \mathrm{M}$ ortho-vanadate, $5 \mu \mathrm{M} \mathrm{NaF}$, and $5 \mathrm{mM} \beta$-glycerol phosphate) and pelleted by centrifugation. Cell pellets were suspended in 2 volumes of PGSK+, and an equal volume of zirconium beads (Biospec Products) added, and cells lysed by vortexing for 12-15 min. Extracts were cleared by centrifugation for $10 \mathrm{~min}$ at $13,000 \times \mathrm{g}$. For $1 \mathrm{D}$ SDS-PAGE, extracts were re-suspended in an equal volume of $2 \times$ SDS sample buffer [72] and denatured at $95^{\circ} \mathrm{C}$ for $5 \mathrm{~min}$. For 2D-SDS-PAGE and 2D-DiGE, extracts were treated with $50 \mu \mathrm{g} / \mathrm{ml}$ DNAse and RNAse (Worthington) for 15 minutes, precipitated with methanol/chloroform and re-suspended in labeling buffer $(2 \mathrm{M}$ thiourea, $7 \mathrm{M}$ urea, $30 \mathrm{mM}$ Tris, $4 \%$ CHAPS) at $25^{\circ} \mathrm{C}$ and the protein concentration determined (Biorad Protein Assay). For 2DSDS-PAGE analysis of GLC7-ProA (YNS23) and glc7E101Q-ProA (YNS27), $30 \mu \mathrm{g}$ was loaded to $7 \mathrm{~cm} \mathrm{pH} \mathrm{4-7}$ Readystrip IPG strips (Biorad) and rehydration and focusing carried out according to the manufacturer's instructions.

\section{Immunoblotting}

Immunoblotting was performed as previously described [65]. Briefly, proteins extracts prepared from GLC7-ProA (YNS23, YNS44) and glc7-E101Q-ProA (YNS26, YNS27) strains were separated on 1D or 2D-SDS-PAGE gels, transferred to PVDF membranes (Millipore) and probed with anti-ProA monoclonal antibodies (1:5000; clone SPA-27, Sigma). Actin was detected using the monoclonal antibodies (1:5000; clone C4, MP Biomedical). Protein/antibody complexes were detected using anti-mouse HRPconjugated secondary antibodies (1:10,000; GE HealthCare) and ECL chemiluminescence (Pierce).

\section{Authors' contributions}

$\mathrm{ML}, \mathrm{TN}$ and NS constructed the strains, conducted the screens and ran data confirmation. JK, HP, MZ and MN helped in the data confirmation. PH, HB and CAM participated in the experimental design and data analysis and helped to draft the manuscript. ML, JV and GL conceived the study, analyzed the data and wrote the manuscript. All authors have read and approved the final manuscript.

\section{Additional material}

\section{Additional file 1}

PP1-mediated phosphate exchange.

Click here for file

[http://www.biomedcentral.com/content/supplementary/1471-

2164-9-336-S1.pdf]

\section{Additional file 2}

Western blot analysis of Glc7-ProA and glc7-E101Q-ProA fusion proteins.

Click here for file

[http://www.biomedcentral.com/content/supplementary/1471-

2164-9-336-S2.pdf]

\section{Additional file 3}

SGA and random spore analysis methods.

Click here for file

[http://www.biomedcentral.com/content/supplementary/1471-

2164-9-336-S3.pdf]

\section{Additional file 4}

List of genes included in the SGA screens, found as hits in the screens and confirmed as glc7-E101Q SSL by random spore analysis.

Click here for file

[http://www.biomedcentral.com/content/supplementary/14712164-9-336-S4.txt]

\section{Additional file 5}

List of glc7-E101Q SSL genes with and their attributes.

Click here for file

[http://www.biomedcentral.com/content/supplementary/1471-

2164-9-336-S5.xls] 


\section{Additional file 6 \\ Distribution of high-level GO annotations for glc7-E101Q SSL genes. Click here for file \\ [http://www.biomedcentral.com/content/supplementary/1471- 2164-9-336-S6.pdf]}

\section{Acknowledgements}

We thank Damien Damours, Phil Branton, Malcolm Whiteway and all the members of the Vogel, Mandato and Bussey labs for fruitful discussions and support during this project, and acknowledge the Cell Imaging and Analysis Network (CIAN) DiGE and SGA platforms. JV is supported by a New Investigator Award from the Canadian Institutes of Health Research (MSH 69117). CAM is Canada Research Chair. This research was supported by operating grants from the Canadian Institutes of Health Research (MOP64404 to JV and MOP-68970 to CAM), the Natural Sciences and Engineering Research Council (262246-03 to JV and 6040-03 to HB) and infrastructure grants from the Canada Foundation for Innovation to awarded to JV (CFI 7395) and to the Developmental Biology Research Initiative of McGill University (CFI 8298).

\section{References}

I. Andrews PD, Stark MJ: Type I protein phosphatase is required for maintenance of cell wall integrity, morphogenesis and cell cycle progression in Saccharomyces cerevisiae. J Cell Sci 2000, I I 3(Pt 3):507-520.

2. Dobbelaere J, Gentry MS, Hallberg RL, Barral Y: Phosphorylationdependent regulation of septin dynamics during the cell cycle. Dev Cell 2003, 4(3):345-357.

3. Pinsky BA, Kotwaliwale CV, Tatsutani SY, Breed CA, Biggins S: GIc7/ protein phosphatase I regulatory subunits can oppose the IpI I/aurora protein kinase by redistributing Glc7. Mol Cell Biol 2006, 26(7):2648-2660.

4. Stegmeier F, Amon A: Closing mitosis: the functions of the Cdcl 4 phosphatase and its regulation. Annu Rev Genet 2004, 38:203-232.

5. Bloecher A, Tatchell K: Dynamic localization of protein phosphatase type I in the mitotic cell cycle of Saccharomyces cerevisiae. I Cell Biol 2000, I49(I): | 25-|40.

6. Sakumoto N, Matsuoka I, Mukai Y, Ogawa N, Kaneko Y, Harashima S: A series of double disruptants for protein phosphatase genes in Saccharomyces cerevisiae and their phenotypic analysis. Yeast 2002, I 9(7):587-599.

7. Collins SR, Miller KM, Maas NL, Roguev A, Fillingham J, Chu CS, Schuldiner M, Gebbia M, Recht J, Shales M, Ding H, Xu H, Han J, Ingvarsdottir K, Cheng B, Andrews B, Boone C, Berger SL, Hieter P Zhang Z, Brown GW, Ingles C), Emili A, Allis CD, Toczyski DP, Weissman JS, Greenblatt JF, Krogan NJ: Functional dissection of protein complexes involved in yeast chromosome biology using a genetic interaction map. Nature 2007, 446(7 I 37):806-810

8. Decourty L, Saveanu C, Zemam K, Hantraye F, Frachon E, Rousselle JC, Fromont-Racine $M$, Jacquier A: Linking functionally related genes by sensitive and quantitative characterization of genetic interaction profiles. Proc Natl Acad Sci USA 2008, I 05( I 5):582 I-5826.

9. Pan X, Ye P, Yuan DS, Wang X, Bader JS, Boeke JD: A DNA integrity network in the yeast Saccharomyces cerevisiae. Cell 2006, I 24(5): 1069-108I.

10. Pan X, Yuan DS, Xiang D, Wang X, Sookhai-Mahadeo S, Bader JS, Hieter $P$, Spencer F, Boeke JD: A robust toolkit for functional profiling of the yeast genome. Mol Cell 2004, I 6(3):487-496.

II. Schuldiner M, Collins SR, Thompson NJ, Denic V, Bhamidipati A Punna T, Ihmels J, Andrews B, Boone C, Greenblatt JF, Weissman JS, Krogan NJ: Exploration of the function and organization of the yeast early secretory pathway through an epistatic miniarray profile. Cell 2005, I 23(3):507-5I9.
12. Tong AH, Evangelista M, Parsons AB, Xu H, Bader GD, Page N, Robinson $M$, Raghibizadeh S, Hogue CW, Bussey $H$, Andrews B, Tyers $M$, Boone $C$ : Systematic genetic analysis with ordered arrays of yeast deletion mutants. Science 200I, 294(5550):2364-2368.

13. Tong AH, Lesage G, Bader GD, Ding H, Xu H, Xin X, Young J, Berriz GF, Brost RL, Chang M, Chen Y, Cheng X, Chua G, Friesen H, Goldberg DS, Haynes J, Humphries C, He G, Hussein S, Ke L, Krogan N, Li Z, Levinson JN, Lu H, Menard P, Munyana C, Parsons AB, Ryan O, Tonikian R, Roberts T, Sdicu AM, Shapiro J, Sheikh B, Suter B, Wong SL, Zhang LV, Zhu H, Burd CG, Munro S, Sander C, Rine J, Greenblatt J, Peter M, Bretscher A, Bell G, Roth FP, Brown GW, Andrews B, Bussey $\mathrm{H}$, Boone $\mathrm{C}$ : Global mapping of the yeast genetic interaction network. Science 2004, 303(5659):808-8I3.

14. Terrak M, Kerff F, Langsetmo K, Tao T, Dominguez R: Structural basis of protein phosphatase I regulation. Nature 2004, 429(6993):780-784.

15. Wu X, Hart H, Cheng C, Roach PJ, Tatchell K: Characterization of Gaclp, a regulatory subunit of protein phosphatase type I involved in glycogen accumulation in Saccharomyces cerevisiae. Mol Genet Genomics 200I, 265(4):622-635.

16. $\mathrm{Wu} X$, Tatchell $\mathrm{K}$ : Mutations in yeast protein phosphatase type I that affect targeting subunit binding. Biochemistry 200I, 40(25):7410-7420.

17. Ceulemans $\mathrm{H}$, Bollen $\mathrm{M}$ : Functional diversity of protein phosphatase-I, a cellular economizer and reset button. Physiol Rev 2004, 84(I): I-39.

18. Knaus M, Cameroni E, Pedruzzi I, Tatchell K, De Virgilio C, Peter M: The Bud I 4p-GIc7p complex functions as a cortical regulator of dynein in budding yeast. Embo J 2005, 24(I 7):3000-30 I I.

19. Ramaswamy NT, Li L, Khalil M, Cannon JF: Regulation of yeast glycogen metabolism and sporulation by Glc7p protein phosphatase. Genetics 1998, I49(I):57-72.

20. Davierwala AP, Haynes J, Li Z, Brost RL, Robinson MD, Yu L, Mnaimneh S, Ding H, Zhu H, Chen Y, Cheng X, Brown GW, Boone C, Andrews BJ, Hughes TR: The synthetic genetic interaction spectrum of essential genes. Nat Genet 2005, 37( I 0): I | 47- I I 52.

21. Drees BL, Thorsson V, Carter GW, Rives AW, Raymond MZ, AvilaCampillo I, Shannon P, Galitski T: Derivation of genetic interaction networks from quantitative phenotype data. Genome Biol 2005, 6(4):R38.

22. Baker SH, Frederick DL, Bloecher A, Tatchell K: Alanine-scanning mutagenesis of protein phosphatase type I in the yeast Saccharomyces cerevisiae. Genetics 1997, I 45(3):6I5-626.

23. Wan J, Xu H, Grunstein M: CDCI 4 of Saccharomyces cerevisiae. Cloning, sequence analysis, and transcription during the cell cycle. J Biol Chem I992, 267( I 6): I I 274- I I 280.

24. Sanz P, Alms GR, Haystead TA, Carlson M: Regulatory interactions between the Regl-Glc7 protein phosphatase and the Snfl protein kinase. Mol Cell Biol 2000, 20(4): | 32 | - | 328.

25. Tu J, Carlson M: REG I binds to protein phosphatase type I and regulates glucose repression in Saccharomyces cerevisiae. Embo J 1995, I 4(23):5939-5946.

26. Stark C, Breitkreutz BJ, Reguly T, Boucher L, Breitkreutz A, Tyers M BioGRID: a general repository for interaction datasets. Nucleic Acids Res 2006:D535-539.

27. Goldberg J, Huang HB, Kwon YG, Greengard P, Nairn AC, Kuriyan J: Three-dimensional structure of the catalytic subunit of protein serine/threonine phosphatase-I. Nature 1995 , 376(6543):745-753.

28. Zhuo S, Clemens JC, Stone RL, Dixon JE: Mutational analysis of a Ser/Thr phosphatase. Identification of residues important in phosphoesterase substrate binding and catalysis. J Biol Chem 1994, 269(42):26234-26238.

29. Bloecher A, Tatchell K: Defects in Saccharomyces cerevisiae protein phosphatase type I activate the spindle/kinetochore checkpoint. Genes Dev 1999, I3(5):517-522.

30. Francisco L, Wang W, Chan CS: Type I protein phosphatase acts in opposition to IpLI protein kinase in regulating yeast chromosome segregation. Mol Cell Biol I994, I 4(7):473 I-4740.

31. Hisamoto N, Sugimoto K, Matsumoto K: The Glc7 type I protein phosphatase of Saccharomyces cerevisiae is required for cell cycle progression in G2/M. Mol Cell Biol 1994, I4(5):3 I58-3 I 65.

32. Sassoon I, Severin FF, Andrews PD, Taba MR, Kaplan KB, Ashford AJ, Stark MJ, Sorger PK, Hyman AA: Regulation of Saccharomyces cerevisiae kinetochores by the type I phosphatase Glc7p. Genes Dev 1999, I3(5):545-555. 
33. Tung HY, Wang W, Chan CS: Regulation of chromosome segregation by Glc8p, a structural homolog of mammalian inhibitor 2 that functions as both an activator and an inhibitor of yeast protein phosphatase I. Mol Cell Biol 1995, I 5(I I):6064-6074.

34. Goshima G, Yanagida M: Establishing biorientation occurs with precocious separation of the sister kinetochores, but not the arms, in the early spindle of budding yeast. Cell 2000, 100(6):619-633.

35. Hieter P, Mann C, Snyder M, Davis RW: Mitotic stability of yeast chromosomes: a colony color assay that measures nondisjunction and chromosome loss. Cell 1985, 40(2):38I-392.

36. Stuart JS, Frederick DL, Varner CM, Tatchell K: The mutant type I protein phosphatase encoded by glc7-I from Saccharomyces cerevisiae fails to interact productively with the GACIencoded regulatory subunit. Mol Cell Biol 1994, I 4(2):896-905.

37. Anderson $C$, Tatchell $K$ : Hyperactive glycogen synthase mutants of Saccharomyces cerevisiae suppress the glc7-I protein phosphatase mutant. J Bacteriol 200I, I 83(3):82I-829.

38. Tu J, Carlson M: The GLC7 type I protein phosphatase is required for glucose repression in Saccharomyces cerevisiae. Mol Cell Biol 1994, I4(10):6789-6796.

39. Sanz P, Ludin K, Carlson M: Sip5 interacts with both the Reg I/ Glc7 protein phosphatase and the SnfI protein kinase of Saccharomyces cerevisiae. Genetics 2000, I54(I):99-107.

40. Enjalbert B, Parrou JL, Vincent O, Francois J: Mitochondrial respiratory mutants of Saccharomyces cerevisiae accumulate glycogen and readily mobilize it in a glucose-depleted medium. Microbiology 2000, I46(Pt I0):2685-2694.

4I. Kim G, Sikder H, Singh KK: A colony color method identifies the vulnerability of mitochondria to oxidative damage. Mutagenesis 2002, I7(5):375-38I.

42. Tachikawa H, Bloecher A, Tatchell K, Neiman AM: A Giplp-GIc7p phosphatase complex regulates septin organization and spore wall formation. J Cell Biol 200I, I55(5):797-808.

43. Hochwagen $A$, Tham $W H$, Brar GA, Amon A: The FK506 binding protein $\mathrm{Fpr} 3$ counteracts protein phosphatase I to maintain meiotic recombination checkpoint activity. Cell 2005, I 22(6):86 I-873.

44. Bailis JM, Roeder GS: Pachytene exit controlled by reversal of Mek I-dependent phosphorylation. Cell 2000, I0 I(2):2II-22I.

45. Boeke JD, LaCroute F, Fink GR: A positive selection for mutants lacking orotidine-5'-phosphate decarboxylase activity in yeast: 5-fluoro-orotic acid resistance. Mol Gen Genet 1984, 197(2):345-346.

46. Tavazoie S, Hughes JD, Campbell MJ, Cho RJ, Church GM: Systematic determination of genetic network architecture. Nat Genet 1999, 22(3):28I-285.

47. Ramaswamy V, Williams JS, Robinson KM, Sopko RL, Schultz MC: Global control of histone modification by the anaphase-promoting complex. Mol Cell Biol 2003, 23(24):9136-9/49.

48. Zhang K, Lin W, Latham JA, Riefler GM, Schumacher JM, Chan C, Tatchell K, Hawke DH, Kobayashi R, Dent SY: The Set I methyltransferase opposes IpII aurora kinase functions in chromosome segregation. Cell 2005, I 22(5):723-734.

49. Norden C, Mendoza M, Dobbelaere J, Kotwaliwale CV, Biggins S, Barral $Y$ : The NoCut pathway links completion of cytokinesis to spindle midzone function to prevent chromosome breakage. Cell 2006, I 25(I):85-98

50. Yoshida S, Kono K, Lowery DM, Bartolini S, Yaffe MB, Ohya Y, Pellman D: Polo-like kinase Cdc5 controls the local activation of Rhol to promote cytokinesis. Science 2006, 3 I3(5783): I08-I I I.

5I. Gao XD, Sperber LM, Kane SA, Tong Z, Tong AH, Boone C, Bi E: Sequential and distinct roles of the cadherin domain-containing protein Axl2p in cell polarization in yeast cell cycle. Mol Biol Cell 2007, I8(7):2542-2560.

52. Cullen PJ, Sprague GF Jr: The Glc7p-interacting protein Bud I 4p attenuates polarized growth, pheromone response, and filamentous growth in Saccharomyces cerevisiae. Eukaryot Cell 2002, I(6):884-894.

53. Cheeseman IM, Anderson S, Jwa M, Green EM, Kang J, Yates JR 3rd, Chan CS, Drubin DG, Barnes G: Phospho-regulation of kinetochore-microtubule attachments by the Aurora kinase IpI Ip. Cell 2002, I I I(2): 163-172.

54. Hisamoto N, Frederick DL, Sugimoto K, Tatchell K, Matsumoto K The EGPI gene may be a positive regulator of protein phos- phatase type I in the growth control of Saccharomyces cerevisiae. Mol Cell Biol 1995, I5(7):3767-3776.

55. Lenssen E, James N, Pedruzzi I, Dubouloz F, Cameroni E, Bisig R, Maillet L, Werner M, Roosen J, Petrovic K, Winderickx J, Collart MA, De Virgilio C: The Ccr4-Not complex independently controls both Msn2-dependent transcriptional activation - via a newly identified Glc7/Bud I4 type I protein phosphatase module and TFIID promoter distribution. Mol Cell Biol 2005, 25(I):488-498.

56. Venturi GM, Bloecher A, Williams-Hart T, Tatchell K: Genetic interactions between GLC7, PPZI and PPZ2 in saccharomyces cerevisiae. Genetics 2000, I55(I):69-83.

57. Zeng G, Huang B, Neo SP, Wang J, Cai M: Scd5p mediates phosphoregulation of actin and endocytosis by the type $I$ phosphatase GIc7p in yeast. Mol Biol Cell 2007, I 8( I 2):4885-4898.

58. Bryant NJ, James DE: The Secl p/Muncl 8 (SM) protein, Vps45p, cycles on and off membranes during vesicle transport. J Cell Biol 2003, 16I(4):691-696.

59. Gavin AC, Bosche M, Krause R, Grandi P, Marzioch M, Bauer A, Schultz J, Rick JM, Michon AM, Cruciat CM, Remor M, Hofert C, Schelder M, Brajenovic M, Ruffner H, Merino A, Klein K, Hudak M, Dickson D, Rudi T, Gnau V, Bauch A, Bastuck S, Huhse B, Leutwein C. Heurtier MA, Copley RR, Edelmann A, Querfurth E, Rybin V, Drewes G, Raida M, Bouwmeester T, Bork P, Seraphin B, Kuster B, Neubauer G, Superti-Furga G: Functional organization of the yeast proteome by systematic analysis of protein complexes. Nature 2002, 4I 5(6868): $|4|-\mid 47$.

60. Ho Y, Gruhler A, Heilbut A, Bader GD, Moore L, Adams SL, Millar A Taylor P, Bennett K, Boutilier K, Yang L, Wolting C, Donaldson I, Schandorff S, Shewnarane J, Vo M, Taggart J, Goudreault M, Muskat B, Alfarano C, Dewar D, Lin Z, Michalickova K, Willems AR, Sassi H, Nielsen PA, Rasmussen KJ, Andersen JR, Johansen LE, Hansen LH, Jespersen H, Podtelejnikov A, Nielsen E, Crawford J, Poulsen V, Sorensen BD, Matthiesen J, Hendrickson RC, Gleeson F, Pawson T, Moran MF, Durocher D, Mann M, Hogue CW, Figeys D, Tyers M: Systematic identification of protein complexes in Saccharomyces cerevisiae by mass spectrometry. Nature 2002, 415(6868): $180-183$

6I. Christianson TW, Sikorski RS, Dante M, Shero JH, Hieter P: Multifunctional yeast high-copy-number shuttle vectors. Gene 1992, IIO(I): I19-122.

62. Longtine MS, McKenzie A 3rd, Demarini DJ, Shah NG, Wach A, Brachat A, Philippsen P, Pringle JR: Additional modules for versatile and economical PCR-based gene deletion and modification in Saccharomyces cerevisiae. Yeast 1998, I 4(10):953-961.

63. Guthrie C, Fink GR, (eds): Guide to Yeast Genetics and Molecular Biology Part B. New York: Academic Press; 2002.

64. Brachmann CB, Davies A, Cost G], Caputo E, Li J, Hieter P, Boeke JD: Designer deletion strains derived from Saccharomyces cerevisiae S288C: a useful set of strains and plasmids for PCRmediated gene disruption and other applications. Yeast 1998, I4(2): II 15 - I32.

65. Vogel J, Drapkin B, Oomen J, Beach D, Bloom K, Snyder M: Phosphorylation of gamma-tubulin regulates microtubule organization in budding yeast. Dev Cell 200I, I(5):62I-63I.

66. Knop M, Siegers K, Pereira G, Zachariae W, Winsor B, Nasmyth K Schiebel E: Epitope tagging of yeast genes using a PCR-based strategy: more tags and improved practical routines. Yeast 1999, I 5( I0B):963-972.

67. Sikorski RS, Hieter P: A system of shuttle vectors and yeast host strains designed for efficient manipulation of DNA in Saccharomyces cerevisiae. Genetics 1989, I22(I): 19-27.

68. Huffaker TC, Thomas JH, Botstein D: Diverse effects of betatubulin mutations on microtubule formation and function. Cell Biol 1988, 106(6): 1997-2010.

69. Stearns T, Botstein D: Unlinked noncomplementation: isolation of new conditional-lethal mutations in each of the tubulin genes of Saccharomyces cerevisiae. Genetics 1988, I I 9(2):249-260.

70. Dien BS, Peterson MS, Srienc F: Cell-cycle analysis of Saccharomyces cerevisiae. Methods Cell Biol I994, 42(Pt B):457-475.

71. Winzeler EA, Shoemaker DD, Astromoff A, Liang H, Anderson K, Andre B, Bangham R, Benito R, Boeke JD, Bussey H, Chu AM, Connelly C, Davis K, Dietrich F, Dow SW, El Bakkoury M, Foury F, Friend SH, Gentalen E, Giaever G, Hegemann JH, Jones T, Laub M, Liao H, Liebundguth N, Lockhart DJ, Lucau-Danila A, Lussier M, M'Rabet N, 
Menard P, Pai C, Rebischung C, Revuelta JL, Riles L, Roberts C], RossMacdonald P, Scherens B, Snyder M, Sookhai-Mahadeo S, Storms RK, Veronneau S, Voet M, Volckaert G, Ward TR, Wysocki R, Yen G, Yu K, Zimmermann K, Philippsen P, Johnston M, Davis RW: Functional characterization of the $S$. cerevisiae genome by gene deletion and parallel analysis. Science 1999, 285(5429):90I-906.

72. Laemmli UK: Cleavage of structural proteins during the assembly of the head of bacteriophage T4. Nature 1970, 227(5259):680-685.

Publish with Biomed Central and every scientist can read your work free of charge

"BioMed Central will be the most significant development for disseminating the results of biomedical research in our lifetime. " Sir Paul Nurse, Cancer Research UK

Your research papers will be:

- available free of charge to the entire biomedical community

- peer reviewed and published immediately upon acceptance

- cited in PubMed and archived on PubMed Central

- yours - you keep the copyright

Submit your manuscript here:

http://www.biomedcentral.com/info/publishing_adv.asp
Biomedcentral 